\title{
SUBTASK 5.1 - EFFECTS OF SODIUM AND CALCIUM IN LIGNITE ON THE PERFORMANCE OF ACTIVATED CARBON PRODUCTS
}

Final Report

(For the period April 1, 2000, through November 30, 2001)

Prepared for:

AAD Document Control

U.S. Department of Energy

National Energy Technology Laboratory

PO Box 10940, MS 921-107

Pittsburgh, PA 15236-0940

Cooperative Agreement No. DE-FC26-98FT40320

Performance Monitor: Dr. Richard B. Read

Prepared by:

Edwin S. Olson Kurt E. Eylands

Daniel J. Stepan

Energy \& Environmental Research Center University of North Dakota PO Box 9018

Grand Forks, ND 58202-9018 


\section{DISCLAIMER}

This report was prepared as an account of work sponsored by an agency of the United States Government. Neither the United States Government, nor any agency thereof, nor any of their employees makes any warranty, express or implied, or assumes any legal liability or responsibility for the accuracy, completeness, or usefulness of any information, apparatus, product, or process disclosed or represents that its use would not infringe privately owned rights. Reference herein to any specific commercial product, process, or service by trade name, trademark, manufacturer, or otherwise does not necessarily constitute or imply its endorsement, recommendation, or favoring by the United States Government or any agency thereof. The views and opinions of authors expressed herein do not necessarily state or reflect those of the United States Government or any agency thereof.

This report is available to the public from the National Technical Information Service, U.S. Department of Commerce, 5285 Port Royal Road, Springfield, VA 22161; phone orders accepted at (703) $487-4650$.

\section{ACKNOWLEDGMENT}

This report was prepared with the support of the U.S. Department of Energy (DOE) National Energy Technology Laboratory Cooperative Agreement No. DE-FC26-98FT40320. However, any opinions, findings, conclusions, or recommendations expressed herein are those of the authors(s) and do not necessarily reflect the views of DOE.

\section{EERC DISCLAIMER}

LEGAL NOTICE This research report was prepared by the Energy \& Environmental Research Center (EERC), an agency of the University of North Dakota, as an account of work sponsored by the U.S. Department of Energy. Because of the research nature of the work performed, neither the EERC nor any of its employees makes any warranty, express or implied, or assumes any legal liability or responsibility for the accuracy, completeness, or usefulness of any information, apparatus, product, or process disclosed, or represents that its use would not infringe privately owned rights. Reference herein to any specific commercial product, process, or service by trade name, trademark, manufacturer, or otherwise does not necessarily constitute or imply its endorsement or recommendation by the EERC. 


\section{TABLE OF CONTENTS}

LIST OF FIGURES $\ldots \ldots \ldots \ldots \ldots \ldots \ldots \ldots \ldots \ldots \ldots \ldots \ldots \ldots \ldots$ ii

LIST OF TABLES $\ldots \ldots \ldots \ldots \ldots \ldots \ldots \ldots \ldots \ldots \ldots \ldots \ldots \ldots \ldots \ldots \ldots \ldots \ldots \ldots \ldots$

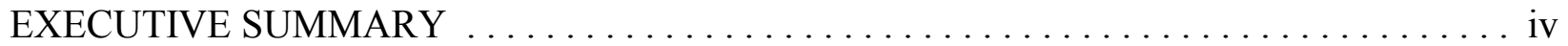

INTRODUCTION $\ldots \ldots \ldots \ldots \ldots \ldots \ldots \ldots \ldots \ldots \ldots \ldots \ldots \ldots \ldots \ldots \ldots \ldots$

GOALS AND OBJECTIVES $\ldots \ldots \ldots \ldots \ldots \ldots \ldots \ldots \ldots \ldots \ldots \ldots \ldots \ldots \ldots$

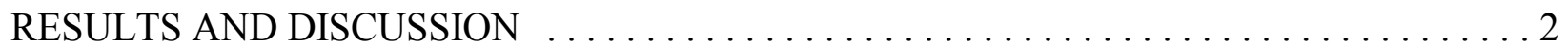

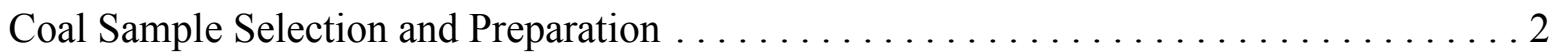

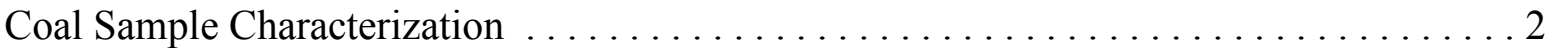

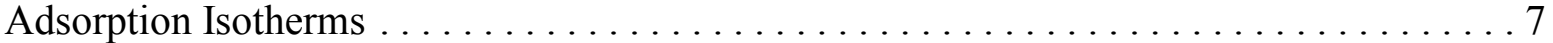

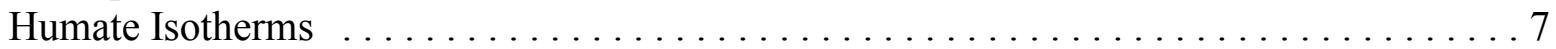

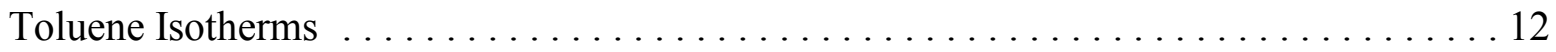

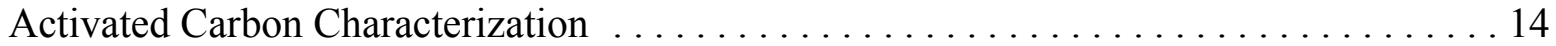

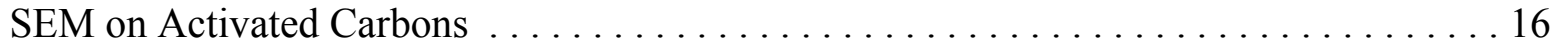

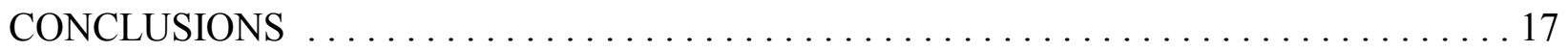

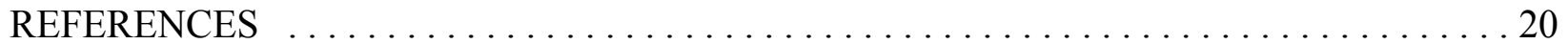




\section{LIST OF FIGURES}

1 An SEM photomicrograph of the low-Na and low-Ca coal showing small pores where Na minerals were removed $\ldots \ldots \ldots \ldots \ldots \ldots \ldots \ldots \ldots \ldots \ldots$

2 Freundlich humate isotherm for high-sodium carbon $\ldots \ldots \ldots \ldots \ldots \ldots$

3 Freundlich humate isotherm (high dosage) for high-sodium carbon $\ldots \ldots \ldots \ldots \ldots \ldots$

$4 \quad$ Normalized humate isotherm for high-sodium carbon $\ldots \ldots \ldots \ldots \ldots \ldots$

$5 \quad$ Normalized humate isotherm for high-calcium carbon $\ldots \ldots \ldots \ldots \ldots \ldots \ldots \ldots$

$6 \quad$ Normalized humate isotherm for low-sodium, low-calcium carbon $\ldots \ldots \ldots \ldots \ldots 11$

$7 \quad$ Normalized humate isotherm for low-sodium, low-calcium carbon No. $2 \ldots \ldots \ldots \ldots 11$

$8 \quad$ Freundlich toluene isotherm for high-sodium carbon $\ldots \ldots \ldots \ldots \ldots \ldots \ldots \ldots \ldots$

$9 \quad$ Normalized toluene isotherm for high-sodium carbon $\ldots \ldots \ldots \ldots \ldots \ldots \ldots \ldots$

10 Freundlich toluene isotherm for high-calcium carbon $\ldots \ldots \ldots \ldots \ldots \ldots \ldots \ldots$

11 Normalized toluene isotherm for high-calcium carbon $\ldots \ldots \ldots \ldots \ldots \ldots \ldots$

12 Normalized toluene isotherm for low-sodium, low-calcium carbon $\ldots \ldots \ldots \ldots \ldots 15$

13 Normalized toluene isotherm for low-sodium, low-calcium carbon No. $2 \ldots \ldots \ldots \ldots$

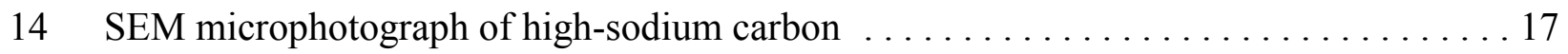

15 SEM microphotograph of high-calcium carbon $\ldots \ldots \ldots \ldots \ldots \ldots \ldots \ldots \ldots \ldots \ldots \ldots$

16 SEM microphotograph of low-sodium, low-calcium carbon $\ldots \ldots \ldots \ldots \ldots \ldots \ldots$ 


\section{LIST OF TABLES}

1 Cluster Analysis Results of the Feed Coal by Size Range $\ldots \ldots \ldots \ldots \ldots \ldots \ldots \ldots$

2 Cluster Analysis Results of the Low-Ca and Low-Na Coal by Size Range . . . . . . . . . 5

3 Cluster Analysis Results for the High-Ca Coal by Size Range $\ldots \ldots \ldots \ldots \ldots \ldots \ldots .6$

4 Activated Carbon Surface Area and Porosity Data . . . . . . . . . . . . . . . 16 


\section{SUBTASK 5.1 - EFFECTS OF SODIUM AND CALCIUM CONTENT IN LIGNITE ON THE PERFORMANCE OF ACTIVATED CARBON PRODUCTS}

\section{EXECUTIVE SUMMARY}

Powdered activated carbon (PAC) has traditionally been used by the water treatment industry for the removal of compounds contributing to taste and odor problems. PAC also has the potential to remove naturally occurring organic matter (NOM) from raw waters prior to disinfection, thus controlling the formation of regulated disinfection by-products (DBPs). Many small water systems are currently using PAC for taste and odor control and have the potential to use PAC for controlling DBPs.

The Energy \& Environmental Research Center has been working on the development of a PAC product to remove NOM from surface water supplies to prevent the formation of carcinogenic DBPs during chlorination. During previous studies, the sodium and calcium content of the lignites showed a significant effect on the sorption capacity of the activated carbon product. As much as a $130 \%$ increase in the humic acid sorption capacity of a PAC produced from a high-sodium-content lignite was observed.

During this study, activated carbons were prepared from three coals representing high-sodium, low-sodium-low-calcium, and high-calcium compositions in two steps, an initial char formation followed by mild activation with steam to avoid excessive burnout. This set of carbons was characterized with respect to physical and chemical properties. The BET (Brunauer-Emmett-Teller) nitrogen adsorption isotherms gave relatively low surface areas (ranging from 245 to $370 \mathrm{~m}^{2} / \mathrm{g}$ ).

The lowest-BET area was obtained for the high-sodium carbon, which can be attributed to enlargement of micropores as a result of sodium-catalyzed gasification reaction of the carbon structure. This hypothesis is consistent with the scanning electron microscopy microprobe analyses, which show that in both the coal and the activated carbon from this coal, the sodium is distributed over both the carbon structure and the mineral particles. Thus it is initially associated with carboxylate groups on the coal and then as sodium oxide or other active form in close proximity to the carbon and is, therefore, readily available for catalysis of gasification.

Humate adsorption isotherms for the high-sodium carbon gave superior results as defined by very high intercepts in modified Freundlich plots. Thus the high-sodium carbon will be considerably more effective in reducing the humate concentration for a given carbon dosage. Analysis of adsorption isotherms indicated the results were consistent with the hypothesis that only the larger pores are effective for binding the large humate molecules, and that the larger pores developed during activation of the high-sodium char give the appropriate macropore structure for humate binding.

Toluene adsorption isotherms indicated that the high-calcium carbon and the low-calcium, low-sodium carbon were superior to the high-sodium carbon for small molecules in aqueous solution, but not as effective as a Calgon F-400 commercial activated carbon. This is consistent with 
the low-BET surface areas observed for the lignite-derived carbons, and thus there are a lower number of sites for binding the smaller toluene molecule in these carbons. 


\section{SUBTASK 5.1 - EFFECTS OF SODIUM AND CALCIUM CONTENT IN LIGNITE ON THE PERFORMANCE OF ACTIVATED CARBON PRODUCTS}

\section{INTRODUCTION}

New federal drinking water regulations have been promulgated to restrict the levels of disinfection by-products (DBPs) in finished public water supplies. DBPs are suspected carcinogens and are formed when organic material is partially oxidized by disinfectants commonly used in the water treatment industry. Additional federal mandates are expected in the near future that will also affect public water suppliers with respect to DBPs.

These new federal drinking water regulations may require public water suppliers to adjust treatment practices or incorporate additional treatment operations into their existing treatment trains. Many options have been identified, including membrane processes, granular activated carbon, powered activated carbon (PAC), enhanced coagulation and/or softening, and alternative disinfectants (e.g., chlorine dioxide, ozone, and chloramines). Of the processes being considered, PAC appears to offer an attractive benefit-to-cost advantage for many water treatment plants, particularly small systems (those serving fewer than 10,000 customers).

PAC has traditionally been used by the water treatment industry for the removal of compounds contributing to taste and odor problems. PAC also has the potential to remove naturally occurring organic matter (NOM) from raw waters prior to disinfection, thus controlling the formation of regulated DBPs. Many small water systems are currently using PAC for taste and odor control and have the potential to use PAC for controlling DBPs.

Activated carbons can be produced from a variety of raw materials, including wood, peat, coconut husks, and numerous types of coal. The Energy \& Environmental Research Center (EERC) has been working on the development of a PAC product to remove NOM from surface water supplies to prevent the formation of carcinogenic DBPs during chlorination.

During that study, the sodium and calcium content of the lignites showed a significant effect on the sorption capacity of the activated carbon product. As much as a $130 \%$ increase in the humic acid sorption capacity of a PAC produced from a high-sodium-content lignite was observed. We hypothesize that the sodium and calcium content of the coal plays a significant role in the development of pore structures and pore-size distribution, ultimately producing activated carbon products that have greater sorption capacity for specific contaminants, depending on molecular size.

\section{GOALS AND OBJECTIVES}

The overall goal of this project is to determine the effects of organically and mineralogically associated sodium and calcium content on pore structure and sorption capacity of activated carbon products. Specific objectives include 1) the selection of three different coal samples for analysis and 
testing, 2) detailed analysis of the selected samples by scanning electron microscopy (SEM) and chemical fractionation to determine the distribution of mineral and organic sodium and calcium, 3) preparation of activated carbons from the selected samples using carbonization and steam activation, 4) development of sorption isotherms on a humate and toluene, and 5) characterization of the activated carbon products to determine surface area and pore-size distribution.

\section{RESULTS AND DISCUSSION}

\section{Coal Sample Selection and Preparation}

The activated carbons were prepared for studies relating the carbon properties to the content of metal cations in the coal. A previously used coal containing the very high sodium content was no longer available, so a moderately high-sodium coal (7.2\% sodium) was obtained from the Dakota Gasification Company and used as the test material.

A sample of relatively high calcium content was not available. In order to provide the same coal structure for a valid comparison of test results, the $7 \%$ sodium sample served as the base material in the preparation of the $7 \%$ calcium sample as well as a low-sodium-and-calcium-content sample. The coal was ground and sieved, and $8 \times 20$-mesh particles collected. The coal was ionexchanged with ammonium acetate and mildly heated to produce a low-sodium, low-calcium coal. A portion of that sample was ion-exchanged with calcium acetate to produce the high-calcium sample. These samples were dried and submitted for surface area and SEM studies to determine mineral content and associations.

The three samples were then used to prepare the activated carbons. Each of the samples were carbonized at $400^{\circ} \mathrm{C}$ in a nitrogen atmosphere for 30 minutes, followed by activation with steam at $750^{\circ} \mathrm{C}$ for 30 minutes. These are temperature and residence time conditions that have been used in previous experimentation and were found to produce high-sodium activated carbons with high sorption capacity. These conditions may not necessarily be optimal for the preparation of highcalcium or even low-sodium-low-calcium carbons. As expected, different carbon yields were obtained with each sample, with the low-sodium-low-calcium sample producing the highest yields and the high-sodium samples the lowest. Thus the carbon burnout is greater for the high-sodium coal.

\section{Coal Sample Characterization}

The three coal samples (the original feed coal, low-Na and low-Ca coal, and Ca-added coal) were analyzed using SEM equipped with an energy-dispersive microanalysis system to determine particle chemistry. The analytical technique used was computer-controlled scanning electron microscopy (CCSEM), which is an automated technique that finds, sizes, and determines individual particle chemistry for hundreds or sometimes thousands of particles per sample.

CCSEM uses a backscattered electron image, which merely bounces the electron beam off of the surface of the sample. Since heavier elements tend to be larger, they bounce more electrons back 
to the backscatter detector, giving a brighter signal. In this case, the coal particles are relatively lightelement compounds (primarily C), and show up as dark areas in the backscattered electron image. In contrast, the mineral grains are composed of heavier elements ( $\mathrm{Ca}, \mathrm{Si}, \mathrm{Al}$, and others) and show up as light grey to white areas on the backscattered electron image. After an image is collected, the CCSEM process then sizes the particles above a video threshold set by the operator to recognize only mineral particles and exclude the coal particles. Those particles that satisfy specific size criteria are then chemically analyzed. Three magnifications are used. A 50× magnification is the low magnification, and particles from 22 to $100 \mu \mathrm{m}$ are sized and chemically analyzed. At $250 \times$, particles in the size range of 4.6 to $22 \mu \mathrm{m}$ are analyzed, and at $800 \times$, particle from 1.0 to $4.6 \mu \mathrm{m}$ are examined.

The mineral weight percent of the original feed coal was calculated by the CCSEM process to be approximately $5.2 \mathrm{wt} \%$ on a coal basis. The dominant mineral phases were pyrite (FeS), calcite $\left(\mathrm{CaCO}_{3}\right)$, quartz $\left(\mathrm{SiO}_{\mathrm{s}}\right)$, and several clay minerals (primarily aluminosilicates). Sodium and calcium were detected in many of the mineral phases, with Na being a minor constituent in several of the mineral types. Table 1 shows the results of a multivariate analysis of the CCSEM data from each of the magnifications. In the larger particles (22 to $100 \mu \mathrm{m}$ ), Na was most commonly associated with $\mathrm{Ca}, \mathrm{Fe}, \mathrm{Mg}$, and $\mathrm{S}$, most likely in the form of sulfates of some type. Sodium was also associated with clay minerals (Cluster 3 ) and $\mathrm{Ca}$ (Cluster 5, likely a mixture of calcite and gypsum). In the mediumsized particles (4.6 to $22 \mu \mathrm{m}$ ), $\mathrm{Na}$ was found to be closely associated $\mathrm{Ca}$ (calcium carbonate) and with $\mathrm{Ba}$ and $\mathrm{S}$ (barium sulfate). Na was measured in minor amounts in all of the significant clusters and was the distinguishing feature separating Clusters 1 and 3. The smallest particles (1.0 to $4.6 \mu \mathrm{m})$ contained $\mathrm{Na}$ in the clay minerals (Cluster 1), pyrite (Cluster 2), and with what appears to be apatite (calcium aluminum phosphate) in Cluster 5.

Table 2 shows the results of the cluster analyses from the low-Na, low-Ca coal. While $\mathrm{Na}$ is still present in many of the phases, it is at a considerably lower amount. Figure 1 is an SEM photograph of the low-Na and low-Ca coal that shows several small "pits." These do not show up on either the feed coal or the high-Ca coal. These small holes are interpreted as areas where Nacontaining mineral phases were removed from the coal. The mineral percent on a coal basis calculated by the CCSEM program estimates the total mineral content to be about $2.9 \mathrm{wt} \%$. This does indicate a reduction in the mineral content from the original feed coal.

Table 3 shows the cluster analyses of the high-Ca coal. The $\mathrm{Ca}$ seems to have remained unreactive in all of the size ranges (Cluster 2 in the 22- to $100-\mu \mathrm{m}$ range and Custer 4 in both of the smaller size ranges). Although calcium occurs in a variety of the mineral phases (alufate, silicate, aluminosilicate, phosphate), no calcium can be seen distributed over the carbon phase. Sodium remains at relatively low levels for all of the size ranges. In Tables $1-3$, the clusters are arranged in order of highest to lowest frequency. The last column represents the frequency percent of the 20 least significant clusters. The clusters are measured as Euclidean distances from a cluster centroid based on all of the elements analyzed. The major components usually vary by about \pm 3 to $5 \mathrm{wt} \%$ within a given cluster. 
Table 1. Cluster Analysis Results of the Feed Coal by Size Range

\begin{tabular}{|c|c|c|c|c|c|c|}
\hline $22-100-\mu \mathrm{m}$ Particles & Cluster 1 & Cluster 2 & Cluster 3 & Cluster 4 & Cluster 5 & Other (20 clusters) \\
\hline $\mathrm{Na}$ & 0.12 & 0.51 & 1.59 & 0.08 & 2.0 & \\
\hline $\mathrm{Mg}$ & 0.79 & 0.04 & 0.96 & 0.03 & 1.68 & \\
\hline $\mathrm{Al}$ & 0.07 & 0.03 & 33.28 & 0.44 & 1.79 & \\
\hline $\mathrm{Si}$ & 0.03 & 0.04 & 55.91 & 97.38 & 0.37 & \\
\hline $\mathrm{P}$ & 0.06 & 0.02 & 0.15 & 0.28 & 0.11 & \\
\hline $\mathrm{S}$ & 0.3 & 52.58 & 1.43 & 0.15 & 7.53 & \\
\hline $\mathrm{Cl}$ & 0.03 & 0.03 & 0.04 & 0.08 & 0.47 & \\
\hline $\mathrm{K}$ & 0.03 & 0.02 & 0.74 & 0.08 & 0.74 & \\
\hline $\mathrm{Ca}$ & 97.15 & 0.15 & 2.85 & 0.36 & 82.79 & \\
\hline $\mathrm{Fe}$ & 0.38 & 45.98 & 1.98 & 0.31 & 1.42 & \\
\hline $\mathrm{Ba}$ & 0.27 & 0.05 & 0.39 & 0.13 & 0.84 & \\
\hline $\mathrm{Ti}$ & 0.05 & 0.0 & 0.35 & 0.03 & 0.37 & \\
\hline Frequency, \% & 44.60 & 32.40 & 6.00 & 5.10 & 2.50 & 9.30 \\
\hline 4.6-22- $\mu \mathrm{m}$ Particles & Cluster 1 & Cluster 2 & Cluster 3 & Cluster 4 & Cluster 5 & \\
\hline $\mathrm{Na}$ & 0.99 & 0.2 & 0.1 & 0.43 & 1.55 & \\
\hline $\mathrm{Mg}$ & 0.91 & 0.15 & 0.91 & 0306 & 0.5 & \\
\hline $\mathrm{Al}$ & 0.07 & 0.44 & 0.07 & 0.1 & 0.36 & \\
\hline $\mathrm{Si}$ & 0.05 & 96.36 & 0.05 & 0.23 & 0.55 & \\
\hline $\mathrm{P}$ & 0.01 & 0.24 & 0.01 & 0.01 & 0 & \\
\hline $\mathrm{S}$ & 0.29 & 0.34 & 0.29 & 52.23 & 20.23 & \\
\hline $\mathrm{Cl}$ & 0.04 & 0.03 & 0.04 & 0.01 & 0.05 & \\
\hline $\mathrm{K}$ & 0.03 & 0.14 & 0.03 & 0.04 & 0.18 & \\
\hline $\mathrm{Ca}$ & 96.96 & 0.68 & 96.96 & 0.35 & 2.23 & \\
\hline $\mathrm{Fe}$ & 0.43 & 0.41 & 0.43 & 45.77 & 0.55 & \\
\hline $\mathrm{Ba}$ & 0.24 & 0.23 & 0.24 & 0.1 & 70.86 & \\
\hline $\mathrm{Ti}$ & 0.05 & 0.13 & 0.05 & 0 & 2.68 & \\
\hline Frequency, \% & 26.30 & 22.70 & 21.60 & 20.40 & 3.10 & 5.80 \\
\hline 1.0-4.6- $\mu \mathrm{m}$ Particles & Cluster 1 & Cluster 2 & Cluster 3 & Cluster 4 & Cluster 5 & \\
\hline $\mathrm{Na}$ & 1.86 & 1.01 & 0.49 & 0.33 & 3.5 & \\
\hline $\mathrm{Mg}$ & 1.72 & 0.75 & 0.33 & 1.16 & 2.6 & \\
\hline $\mathrm{Al}$ & 27.82 & 0.88 & 1.19 & 0.64 & 31.1 & \\
\hline $\mathrm{Si}$ & 52.31 & 0.88 & 92.24 & 0.64 & 2.1 & \\
\hline $\mathrm{P}$ & 0.41 & 0.1 & 0.33 & 0.2 & 16.3 & \\
\hline $\mathrm{S}$ & 2.93 & 48.52 & 1.18 & 0.51 & 7.1 & \\
\hline $\mathrm{Cl}$ & 0.3 & 0.13 & 0.12 & 0.15 & 0.5 & \\
\hline $\mathrm{K}$ & 2.76 & 0.1 & 0.33 & 0.15 & 0.5 & \\
\hline $\mathrm{Ca}$ & 4.68 & 2.38 & 2.0 & 94.49 & 27.5 & \\
\hline $\mathrm{Fe}$ & 3.66 & 44.29 & 0.83 & 0.65 & 0.9 & \\
\hline $\mathrm{Ba}$ & 1.06 & 0.26 & 0.47 & 0.55 & 7.1 & \\
\hline $\mathrm{Ti}$ & 0.34 & 0.15 & 0.15 & 0.16 & 0.9 & \\
\hline Frequency, \% & 28.20 & 23.00 & 21.10 & 13.00 & 2.40 & 12.10 \\
\hline
\end{tabular}


Table 2. Cluster Analysis Results of the Low-Ca and Low-Na Coal by Size Range

\begin{tabular}{|c|c|c|c|c|c|c|}
\hline 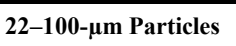 & Cluster 1 & Cluster 2 & Cluster 3 & Cluster 4 & Cluster 5 & Other (20 Clusters) \\
\hline $\mathrm{Na}$ & 0.23 & 0.01 & 0.36 & 0.05 & 0.52 & \\
\hline $\mathrm{Mg}$ & 0.92 & 0.02 & 0.03 & 2.05 & 0.93 & \\
\hline $\mathrm{Al}$ & 33.52 & 0.3 & 0.09 & 0.09 & 9.41 & \\
\hline $\mathrm{Si}$ & 54.84 & 97.78 & 0.19 & 0.05 & 75.59 & \\
\hline $\mathrm{P}$ & 0.28 & 0.19 & 0.01 & 0.05 & 0.41 & \\
\hline $\mathrm{S}$ & 2.08 & 0.1 & 52.15 & 0.09 & 2.45 & \\
\hline $\mathrm{Cl}$ & 0.12 & 0.04 & 0.02 & 0 & 0.31 & \\
\hline $\mathrm{K}$ & 1.68 & 0.05 & 0.01 & 0.02 & 2.17 & \\
\hline $\mathrm{Ca}$ & 3.1 & 0.23 & 0.29 & 96.36 & 3.79 & \\
\hline $\mathrm{Fe}$ & 2.03 & 0.25 & 46.1 & 0.18 & 2.03 & \\
\hline $\mathrm{Ba}$ & 0.42 & 0.28 & 0.06 & 0.32 & 1.24 & \\
\hline $\mathrm{Ti}$ & 0.3 & 0.04 & 0.02 & 0.07 & 0.76 & \\
\hline Frequency, \% & 40.50 & 21.30 & 16.70 & 7.00 & 4.60 & 10.00 \\
\hline 4.6-22- $\mu \mathrm{m}$ Particles & Cluster 1 & Cluster 2 & Cluster 3 & Cluster 4 & Cluster 5 & \\
\hline $\mathrm{Na}$ & 0.28 & 0.02 & 0.06 & 1.06 & 0.07 & \\
\hline $\mathrm{Mg}$ & 1.19 & 0.05 & 0.04 & 0.56 & 1.93 & \\
\hline $\mathrm{Al}$ & 30.71 & 0.7 & 0.04 & 1.5 & 0.07 & \\
\hline $\mathrm{Si}$ & 58.29 & 96.39 & 0.04 & 0.75 & 0.07 & \\
\hline $\mathrm{P}$ & 0.2 & 0.23 & 0.01 & 0 & 0.13 & \\
\hline $\mathrm{S}$ & 1.74 & 0.47 & 21.15 & 20.69 & 0.2 & \\
\hline $\mathrm{Cl}$ & 0.1 & 0.06 & 0.09 & 0.25 & 0 & \\
\hline K & 0.97 & 0.11 & 0 & 0.06 & 0 & \\
\hline $\mathrm{Ca}$ & 2.01 & 0.56 & 0.17 & 2.44 & 96.33 & \\
\hline $\mathrm{Fe}$ & 3.5 & 0.4 & 78.43 & 0.88 & 0.4 & \\
\hline $\mathrm{Ba}$ & 0.39 & 0.22 & 0.03 & 69.19 & 0.13 & \\
\hline $\mathrm{Ti}$ & 0.21 & 0.11 & 0.01 & 2.31 & 0 & \\
\hline Frequency, \% & 48.90 & 31.80 & 8.20 & 2.30 & 2.10 & 6.60 \\
\hline 1.0-4.6- $\mu \mathrm{m}$ Particles & Cluster 1 & Cluster 2 & Cluster 3 & Cluster 4 & Cluster 5 & \\
\hline $\mathrm{Na}$ & 0.49 & 0.14 & 0.95 & 0.38 & 0.86 & \\
\hline $\mathrm{Mg}$ & 1.15 & 0.29 & 1.56 & 0.1 & 0.79 & \\
\hline $\mathrm{Al}$ & 30.54 & 0.82 & 33.44 & 0.52 & 1.64 & \\
\hline $\mathrm{Si}$ & 55.74 & 92.73 & 1.6 & 1.07 & 3.07 & \\
\hline $\mathrm{P}$ & 0.59 & 0.59 & 18.73 & 0.14 & 0.07 & \\
\hline $\mathrm{S}$ & 2.68 & 1.52 & 7.43 & 49.83 & 20.07 & \\
\hline $\mathrm{Cl}$ & 0.22 & 0.23 & 0.37 & 0.31 & 0.14 & \\
\hline $\mathrm{K}$ & 0.76 & 0.23 & 0.27 & 0.1 & 0.36 & \\
\hline $\mathrm{Ca}$ & 3.31 & 1.69 & 25.3 & 1.31 & 3.0 & \\
\hline $\mathrm{Fe}$ & 3.34 & 0.55 & 1.56 & 45.1 & 0.79 & \\
\hline $\mathrm{Ba}$ & 0.62 & 0.53 & 8.12 & 0.55 & 66.86 & \\
\hline $\mathrm{Ti}$ & 0.29 & 0.19 & 0.48 & 0.07 & 2.14 & \\
\hline Frequency, \% & 49.90 & 20.90 & 14.30 & 5.00 & 2.40 & 7.30 \\
\hline
\end{tabular}


Table 3. Cluster Analysis Results for the High-Ca Coal by Size Range

\begin{tabular}{|c|c|c|c|c|c|c|}
\hline 22-100- $\mu \mathrm{m}$ Particles & Cluster 1 & Cluster 2 & Cluster 3 & Cluster 4 & Cluster 5 & Other (20 Clusters) \\
\hline $\mathrm{Na}$ & 0.32 & 0.04 & 0.26 & 0 & 0.06 & \\
\hline $\mathrm{Mg}$ & 0.01 & 1.47 & 0.67 & 0 & 0.59 & \\
\hline $\mathrm{Al}$ & 0 & 0.09 & 33.09 & 0.15 & 9.24 & \\
\hline $\mathrm{Si}$ & 0 & 0.11 & 55.94 & 98.1 & 81.06 & \\
\hline $\mathrm{P}$ & 0 & 0.06 & 0.15 & 0.15 & 0.06 & \\
\hline $\mathrm{S}$ & 52.17 & 0.37 & 1.38 & 0.05 & 1.24 & \\
\hline $\mathrm{Cl}$ & 0.01 & 0.04 & 0.15 & 0.01 & 0.29 & \\
\hline K & 0.01 & 0.03 & 1.28 & 0.01 & 1.88 & \\
\hline $\mathrm{Ca}$ & 0.05 & 96.39 & 3.95 & 0.15 & 2.94 & \\
\hline $\mathrm{Fe}$ & 46.77 & 0.48 & 1.87 & 0.34 & 1.65 & \\
\hline $\mathrm{Ba}$ & 0.05 & 0.26 & 0.51 & 0.26 & 0.24 & \\
\hline $\mathrm{Ti}$ & 0 & 0.04 & 0.28 & 0.09 & 0.53 & \\
\hline Frequency, \% & 28.50 & 20.60 & 19.10 & 17.60 & 3.70 & 10.30 \\
\hline 4.6-22- $\mu \mathrm{m}$ Particles & Cluster 1 & Cluster 2 & Cluster 3 & Cluster 4 & Cluster 5 & \\
\hline $\mathrm{Na}$ & 0.2 & 0.11 & 0.16 & 0.09 & 0.85 & \\
\hline $\mathrm{Mg}$ & 1.13 & 0.08 & 0.08 & 1.29 & 0.08 & \\
\hline $\mathrm{Al}$ & 31.18 & 0.81 & 0.05 & 0.27 & 0.54 & \\
\hline $\mathrm{Si}$ & 55.83 & 96.1 & 0.18 & 0.18 & 0.38 & \\
\hline $\mathrm{P}$ & 0.27 & 0.22 & 0 & 0 & 0 & \\
\hline $\mathrm{S}$ & 1.75 & 0.33 & 51.87 & 0.17 & 20.08 & \\
\hline $\mathrm{Cl}$ & 0.18 & 0.06 & 0.04 & 0.02 & $\overline{0}$ & \\
\hline $\mathrm{K}$ & 1.01 & 0.12 & 0.03 & 0.02 & 0 & \\
\hline $\mathrm{Ca}$ & 4.08 & 0.7 & 0.44 & 96.38 & 1.92 & \\
\hline $\mathrm{Fe}$ & 3.25 & 0.39 & 46.39 & 0.5 & 0.62 & \\
\hline $\mathrm{Ba}$ & 0.51 & 0.27 & 0.05 & 0.35 & 73.0 & \\
\hline $\mathrm{Ti}$ & 0.19 & 0.1 & 0 & 0.06 & 2.0 & \\
\hline Frequency, \% & 45.00 & 22.30 & 11.50 & 7.40 & 4.20 & 9.40 \\
\hline 1.0-4.6- $\mu \mathrm{m}$ Particles & Cluster 1 & Cluster 2 & Cluster 3 & Cluster 4 & Cluster 5 & \\
\hline $\mathrm{Na}$ & 0.25 & 0.12 & 0.35 & 0.16 & 1.05 & \\
\hline $\mathrm{Mg}$ & 1.22 & 0.23 & 0.23 & 1.14 & 1.1 & \\
\hline $\mathrm{Al}$ & 30.92 & 0.96 & 0.44 & 0.78 & 1.43 & \\
\hline $\mathrm{Si}$ & 55.91 & 92.98 & 0.61 & 0.97 & 1.14 & \\
\hline $\mathrm{P}$ & 0.37 & 0.6 & 0 & 0.08 & 0.1 & \\
\hline $\mathrm{S}$ & 1.93 & 1.52 & 49.32 & 0.62 & 20.0 & \\
\hline $\mathrm{Cl}$ & 0.18 & 0.18 & 0.14 & 0.27 & 0.52 & \\
\hline $\mathrm{K}$ & 1.07 & 0.18 & 0 & 0.05 & 0.19 & \\
\hline $\mathrm{Ca}$ & 3.52 & 1.72 & 1.05 & 94.14 & 5.86 & \\
\hline $\mathrm{Fe}$ & 3.65 & 0.69 & 46.72 & 0.81 & 0.57 & \\
\hline $\mathrm{Ba}$ & 0.42 & 0.3 & 0.49 & 0.46 & 65.52 & \\
\hline $\mathrm{Ti}$ & 0.25 & 0.06 & 0.05 & 0.14 & 2.57 & \\
\hline Frequency, \% & 45.30 & 26.60 & 11.50 & 9.60 & 1.90 & 5.10 \\
\hline
\end{tabular}




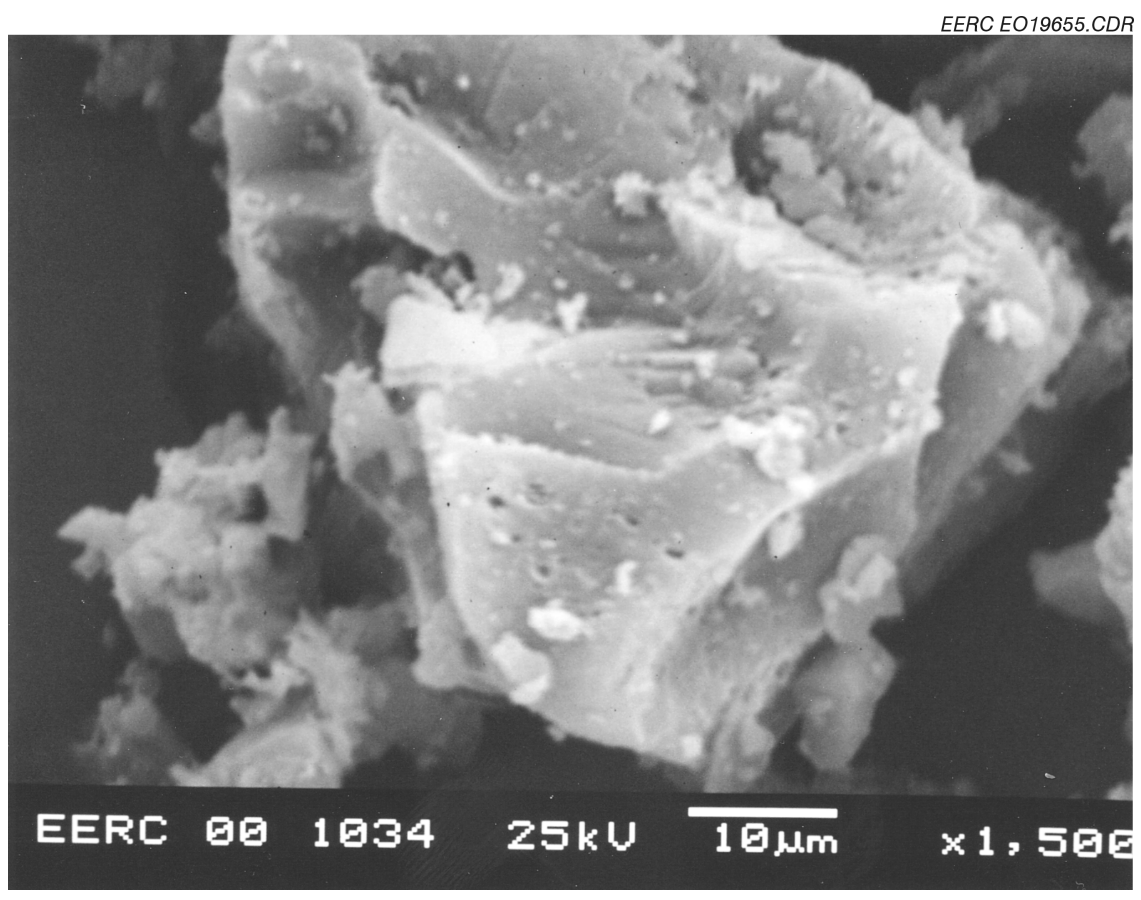

Figure 1. An SEM photomicrograph of the low-Na and low-Ca coal showing small pores where Na minerals were removed.

\section{Adsorption Isotherms}

The activated carbons were washed, dried, and ground to -325-mesh size for further testing. Adsorption isotherms were developed for aqueous humate and toluene solutions.

\section{Humate Isotherms}

To determine the adsorption capacities of the prepared carbons for PAC treatment of a surface water supply containing large amounts of peat-derived humate, such as the Red Lake River, the set of carbons was tested for adsorption of a standard humate solution prepared from a commercial (Aldrich) coal-derived (leonardite) humate. Initially for analysis of the adsorption data, $\log x / m$ was plotted versus $\log c$ to determine the fit to the Freundlich equation (Eq. 1). The carbons exhibited similar nonlinear Freundlich isotherms. The log-log plots from this set of carbons are characterized by a very steep slope at low carbon amounts (high $x / m$ ), and a lower slope at moderate to high carbon amounts.

$$
\log (x / m)=K+n(\log c)
$$

where $x=$ the amount of adsorbed, $m=$ the amount of sorbent, $c=$ the equilibrium concentration in solution, and $K$ and $n$ are constants.

For the activated carbon derived from the high-sodium lignite sample, the addition of $1 \mathrm{mg}$ of carbon resulted in a relatively large decrease in humate concentration in the aqueous phase after 
equilibrium was reached (Figure 2). Thus the $\log x / m$ values were relatively high for this point in the isotherm. But the $\log x / m$ value drops rapidly with larger dosage, giving a steep slope for the lowdosage end of the Freundlich isotherm. Addition of 5-150 mg of carbon produced a much smaller decrease in humate concentration with each increment. Thus the slope remains relatively constant in this portion of the Freundlich isotherm. The plot omitting the low carbon point is shown in Figure 3 , and the slope for this portion was determined to be $n=0.36$.

Earlier adsorption studies with similar lignite-derived carbons and humate solutions also gave nonlinear plots, and in fact, the slopes and intercepts depended significantly on the starting concentration of humate in the experiments. This is indicative of complex selectivity factors involving adsorption of different portions of the polydisperse humate electrolyte. It appears that a large amount of some component is adsorbed, and then the majority of the humate is adsorbed less effectively. Humate molecules differ greatly in size, shape, and polarity, and each of these factors depends on the $\mathrm{pH}$ and ionic strength in the solution. Only a small portion of the humate molecules are expected to bind in micropores; the rest are too large.

To adjust for this complex behavior, the equilibrium concentrations in each experiment were normalized by dividing the unadsorbed humate amount (in $\mathrm{mg}$ ) by the amount of sorbent (in $\mathrm{g}$ ) added (Kilduff et al., 1996). The logs of these normalized concentrations $(\mathrm{c} / \mathrm{m})$ were then plotted versus the logs of the $x / m$ values for each experiment. The normalized isotherm plot for the highsodium carbon is shown in Figure 4. The improved linearity of the plot show that the data fit this normalized model approach much better than the conventional Freundlich model. The resulting slope $(\mathrm{n}=0.27)$ for the high-sodium carbon is, in fact, not too much different from that obtained in the literature for Calgon F400 activated carbon adsorbent with a humate substrate (Kilduff et al., 1996). A different humate was used, so the results cannot be compared exactly. The intercept for the high-

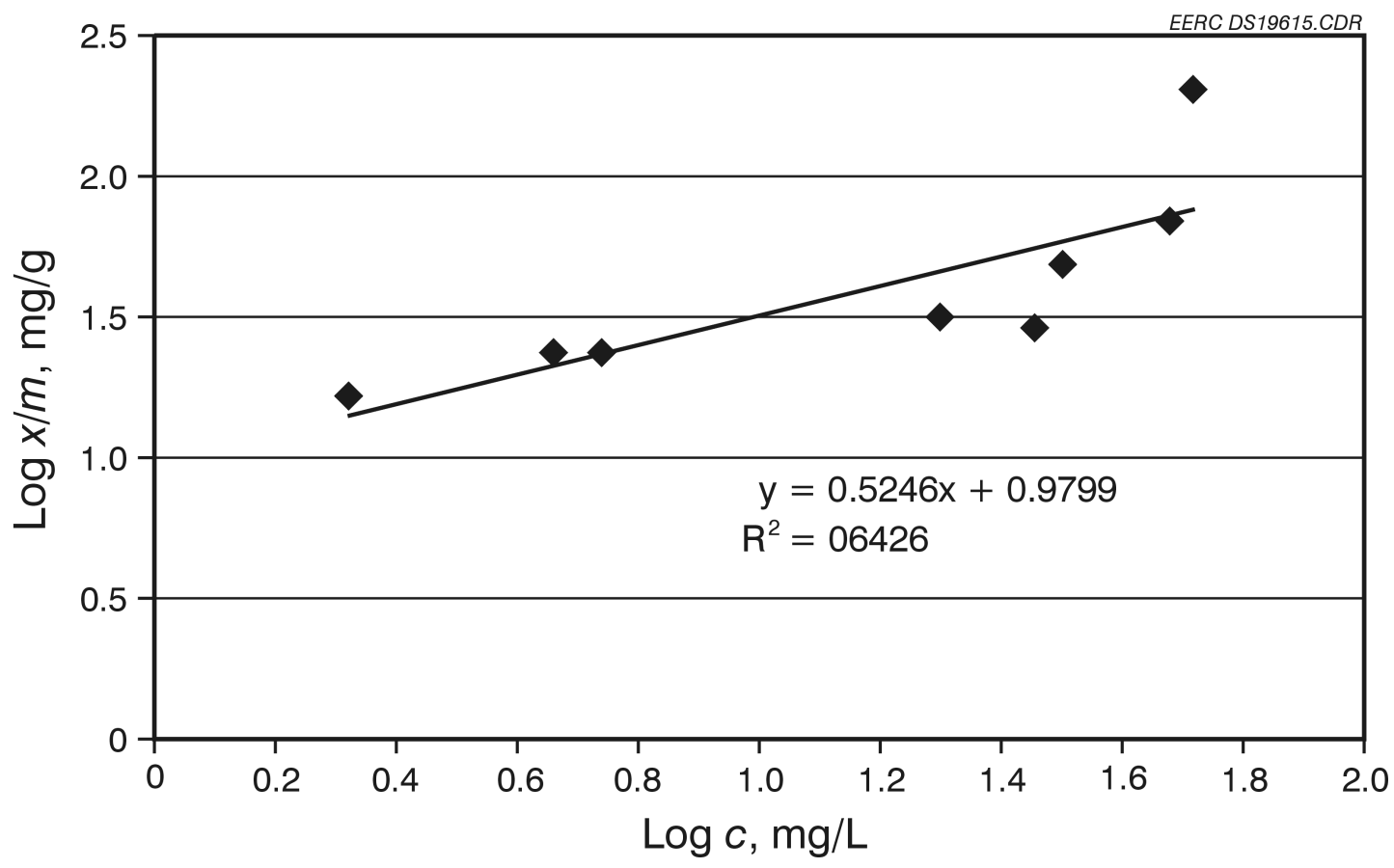

Figure 2. Freundlich humate isotherm for high-sodium carbon. 


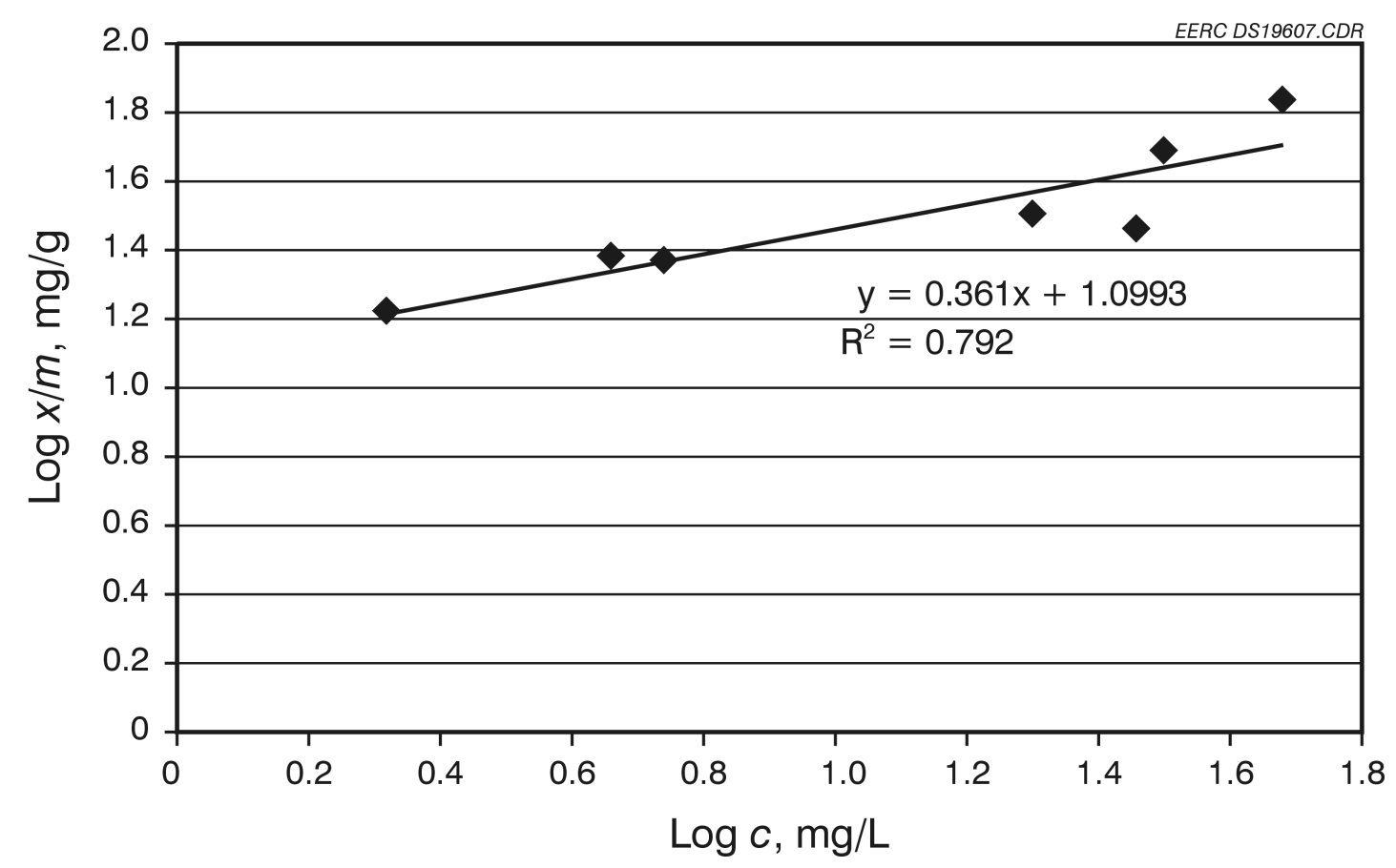

Figure 3. Freundlich humate isotherm (high dosage) for high-sodium carbon.

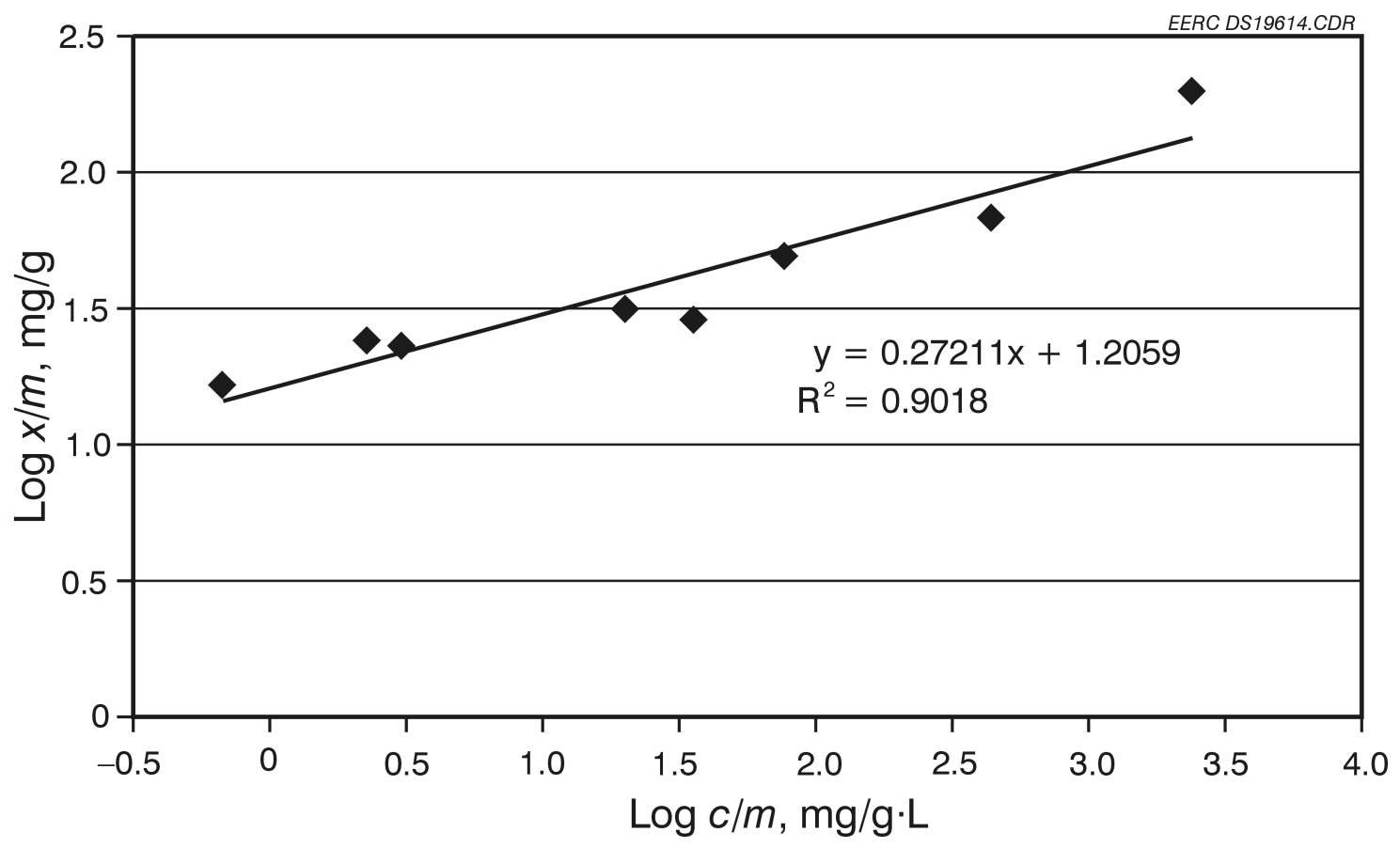

Figure 4. Normalized humate isotherm for high-sodium carbon. 
sodium carbon isotherm is much larger $(\mathrm{K}=1.2)$ than that obtained using the $\mathrm{F} 400$ carbon $(\mathrm{K}=0.8)$. This is significant because it indicates that the carbon will be more effective in reducing the concentration of the humate at a given carbon dosage.

The humate isotherm experiments were conducted for the high-calcium carbon, and the Freundlich isotherm gave a nonlinear plot, with the two lowest dosage points far off the linear regression. Thus the normalized isotherm was plotted using the $\log c / m$ values (Figure 5). Although a higher slope $(n=0.36)$ was obtained for the plot of the high-calcium carbon, the intercept was quite low (0.65). Thus the high-calcium carbon is relatively poor at sorbing humate over most of the carbon dosages.

The low-sodium, low-calcium carbon was similarly evaluated in humate sorption tests. The normalized isotherm plot, of the results is shown in Figure 6. In this plot, the slope $(n=0.29)$ is similar to that of the high-sodium carbon, but the intercept is low $(\mathrm{K}=0.85)$. This reveals again the poorer sorption of humate by this carbon compared with the high-sodium carbon.

For the sample of low-sodium, low-calcium carbon (No. 2) that was overheated during preparation, the normalized isotherm plot (Figure 7) exhibited a somewhat higher slope $(\mathrm{n}=0.31)$ and lower intercept $(\mathrm{K}=0.77)$. Thus the adsorption behavior for humate for this carbon is similar to that of the first low-sodium, low-calcium sample and relatively poor compared to that of the highsodium carbon.

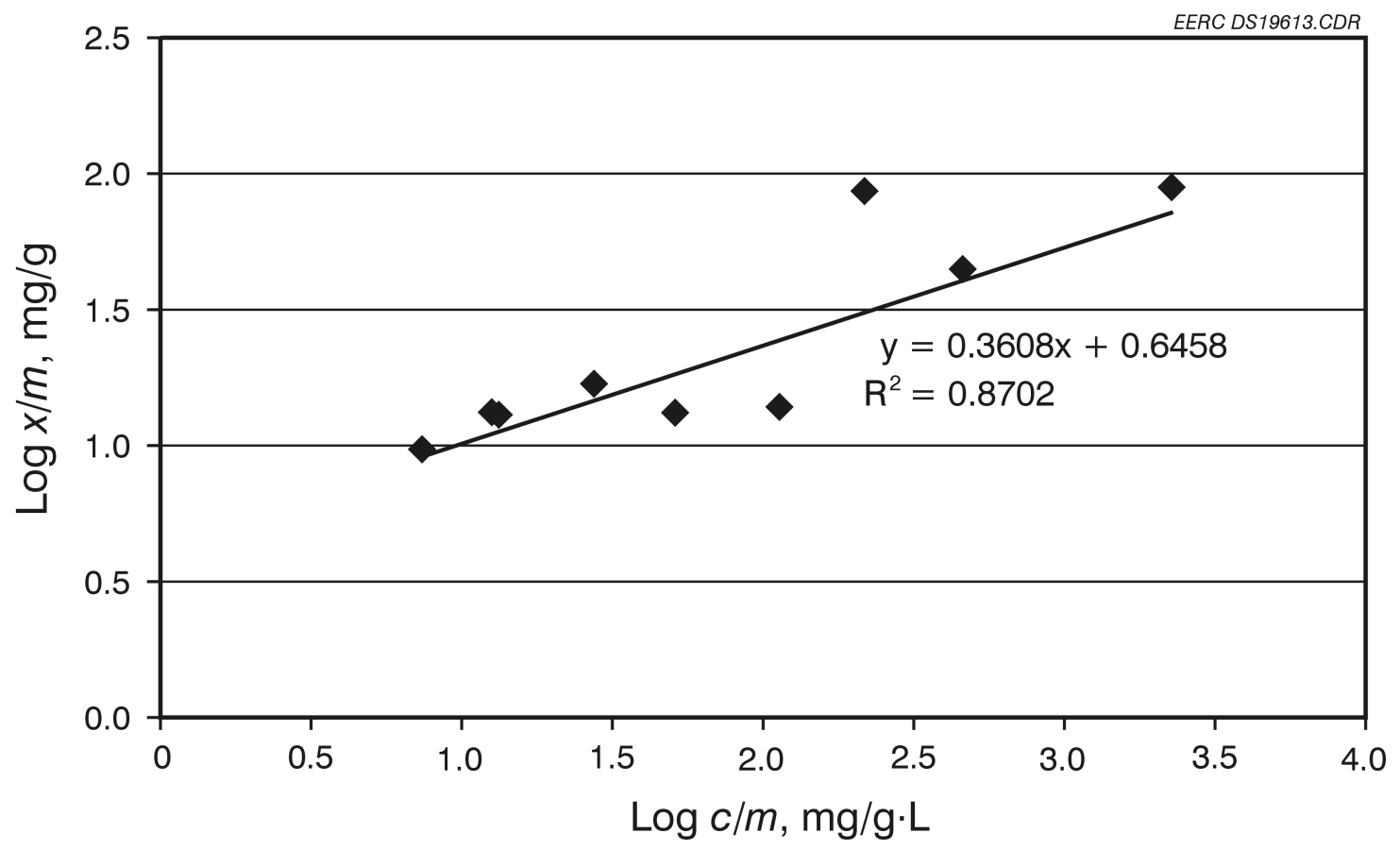

Figure 5. Normalized humate isotherm for high-calcium carbon. 


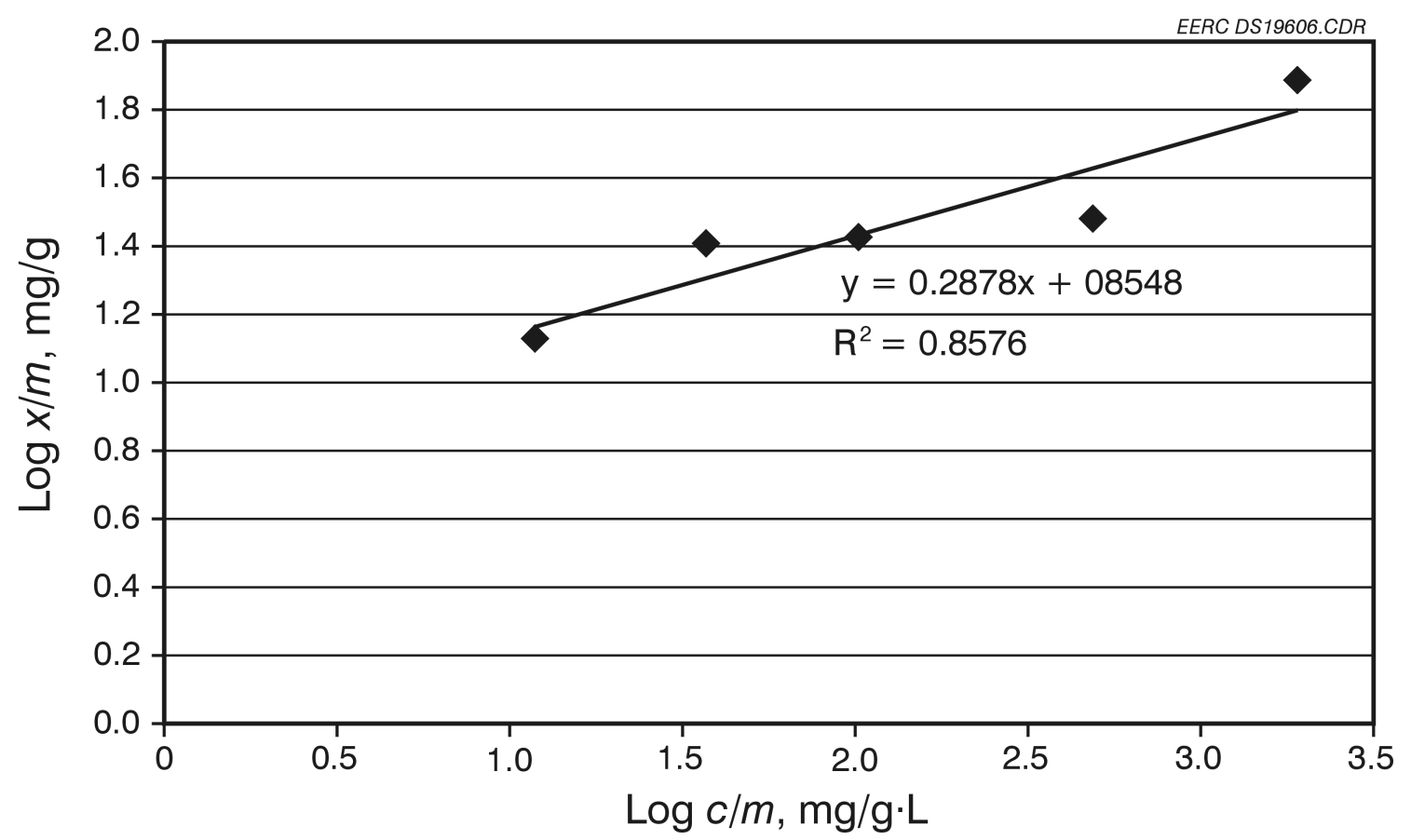

Figure 6. Normalized humate isotherm for low-sodium, low-calcium carbon.

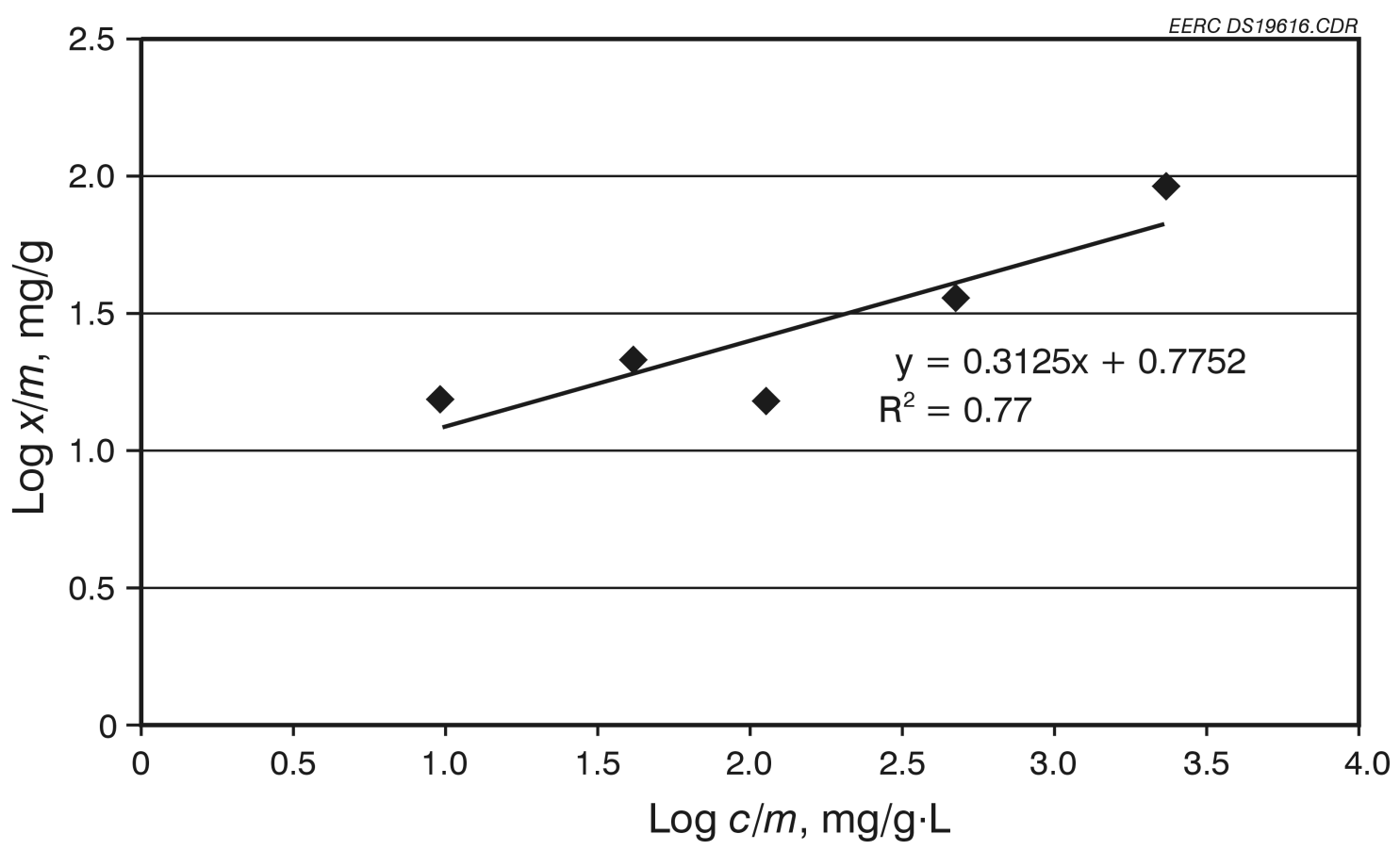

Figure 7. Normalized humate isotherm for low-sodium, low-calcium carbon No. 2. 


\section{Toluene Isotherms}

To predict the behavior of these prepared activated carbons for PAC applications in treating wastewater or hydrocarbon-contaminated water, the isotherms were determined for the adsorption of toluene by the set of carbons. These isotherms were also characterized as having a steeper slope at very low carbon loadings.

The Freundlich isotherm for toluene adsorption by the high-sodium carbon is shown in Figure 8 . The $\mathrm{R}^{2}$ for the plot was very low because of the steep slope corresponding to the low carbon amounts. The intercept was quite low for the toluene adsorption. The normalized isotherm plot using $\log c / m$ is also shown (Figure 9) for this carbon. Now, reasonable values are obtained for the slope and intercept. Although this plot improved the linearity by a significant factor, it is not yet clear why it should, since the toluene is a homogeneous solute. The sorbent does not likely have a homogeneous distribution of pores, that is, it may have a significant number of pores of every size. There is really nothing in the literature to inform us of the effect of this morphology on the isotherms.

The Freundlich toluene isotherm for the high-calcium carbon (Figure 10) was much more linear except for the lowest carbon loading. The normalized plot using log $c / m$ (Figure 11) gave an improvement in linearity. The slope and intercept for the toluene isotherm with the high-calcium carbon were very similar to those of the high-sodium carbon. This indicates that the microporosity of these two carbons should be fairly similar.

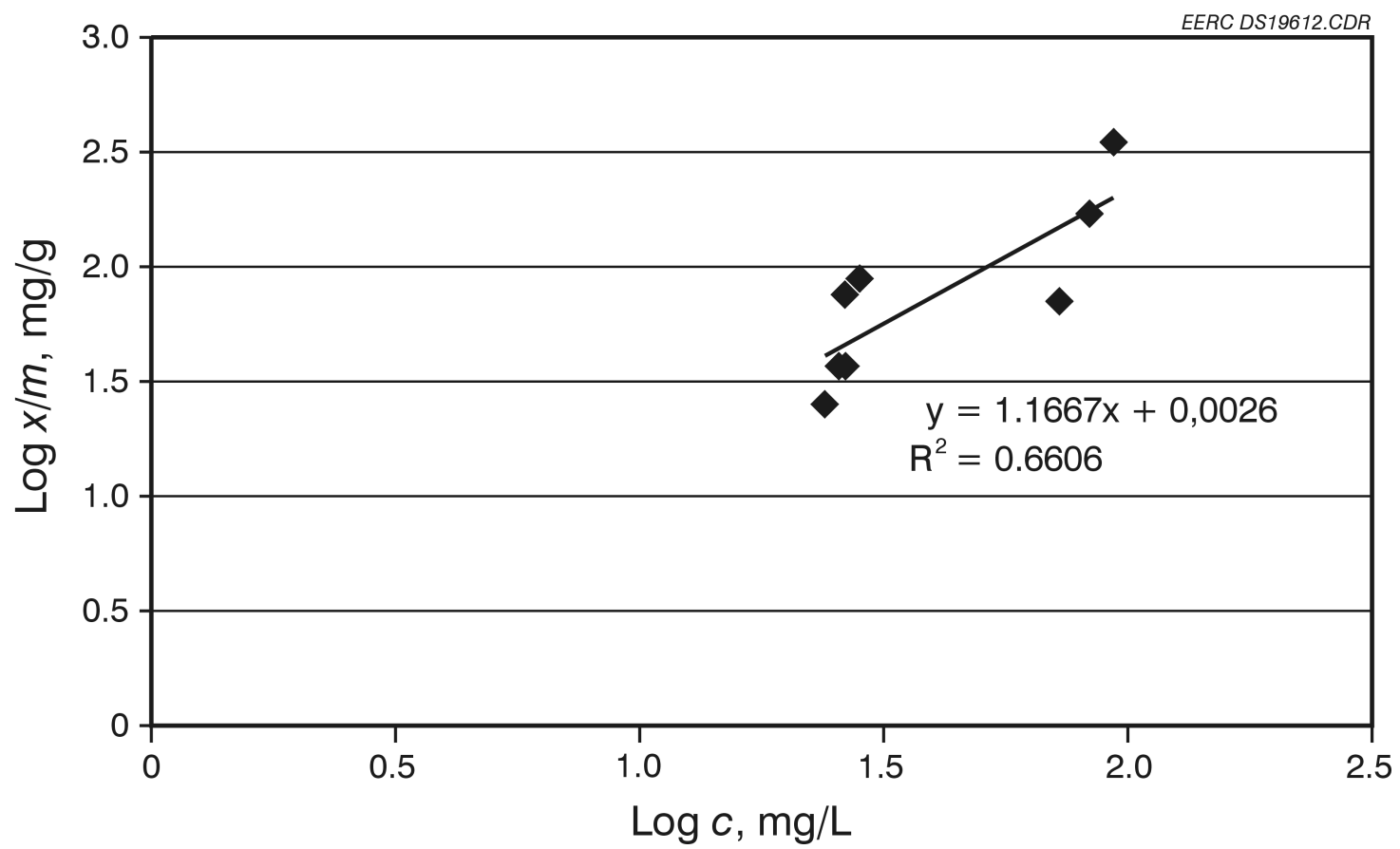

Figure 8. Freundlich toluene isotherm for high-sodium carbon. 


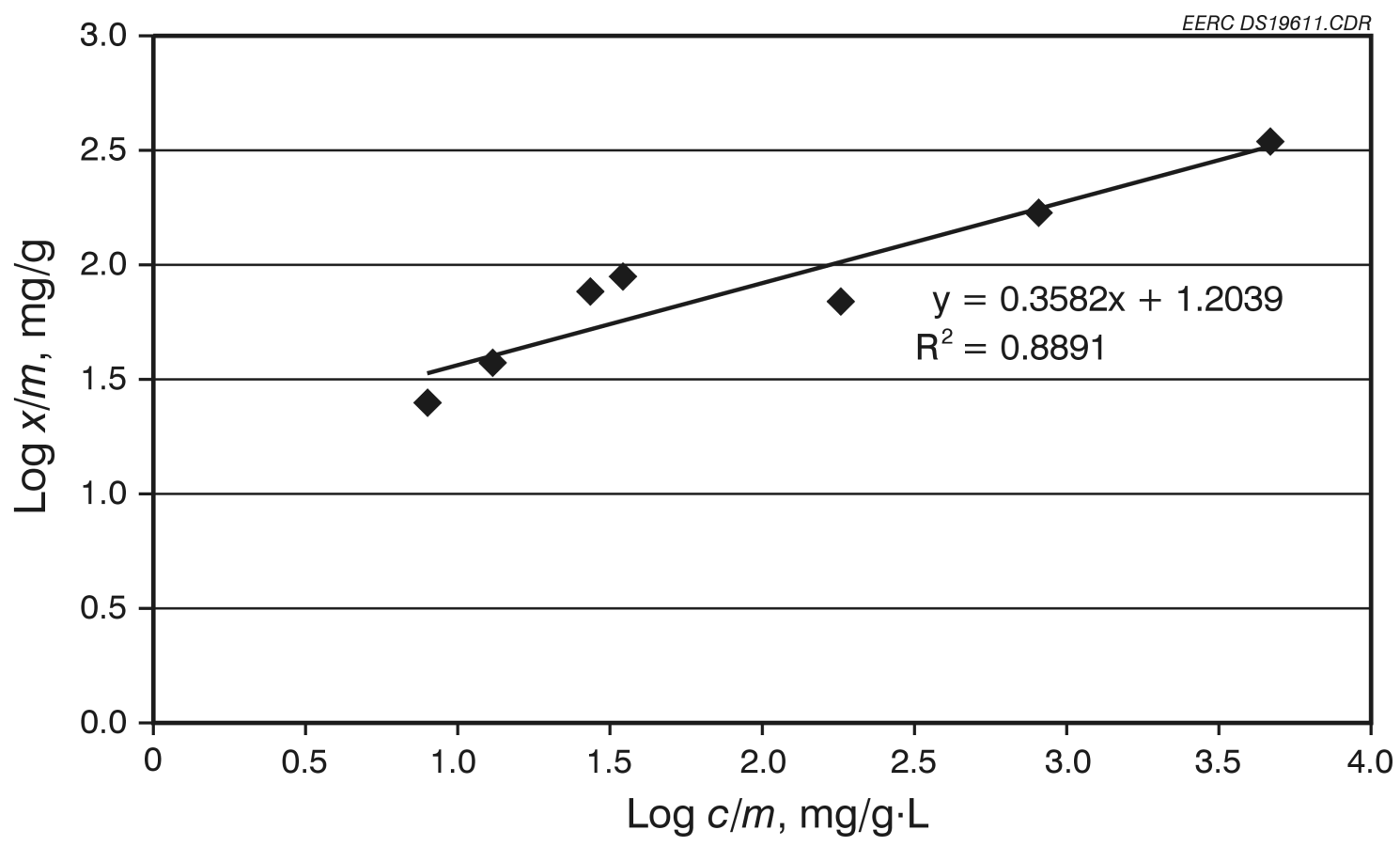

Figure 9. Normalized toluene isotherm for high-sodium carbon.

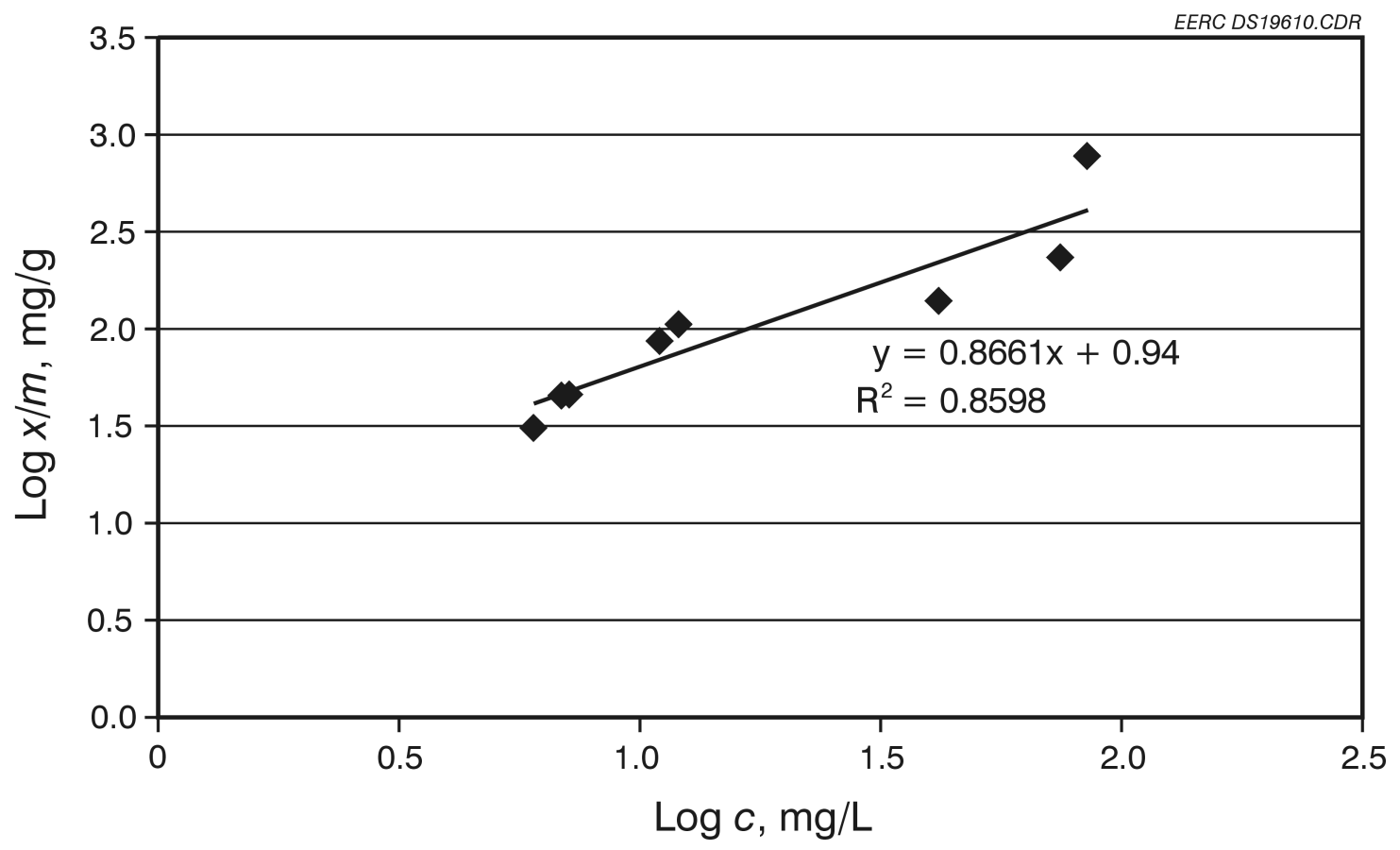

Figure 10. Freundlich toluene isotherm for high-calcium carbon. 


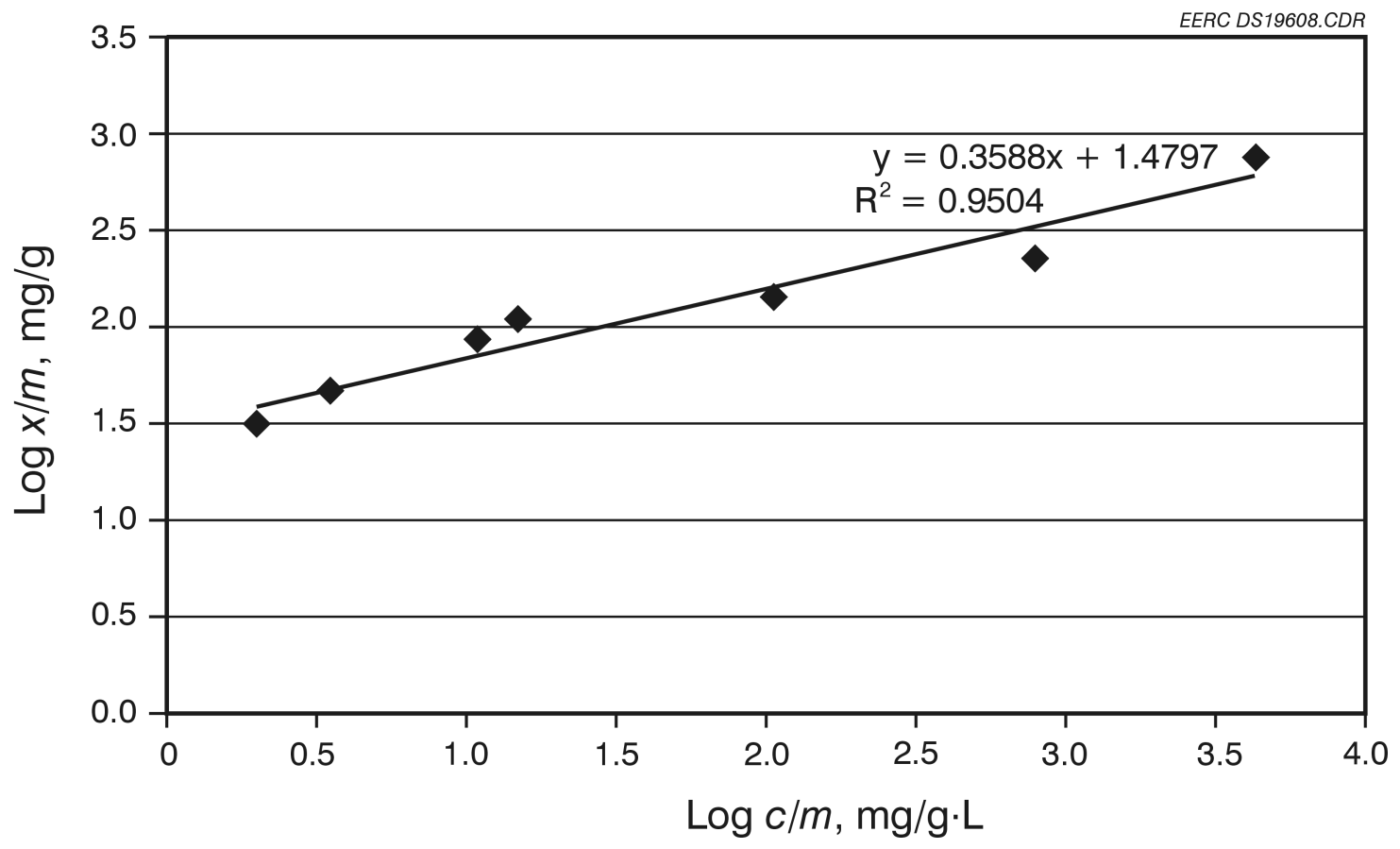

Figure 11. Normalized toluene isotherm for high-calcium carbon.

The Freundlich toluene adsorption isotherms for the low-sodium, low-calcium carbons were very similar to the high-calcium carbon. The normalized isotherms (Figures 12 and 13) showed good linearity. The slope and intercept values of the normalized plots of these samples were also similar to the normalized plots of the high-sodium and high-calcium carbons.

\section{Activated Carbon Characterization}

Fresh samples of the activated carbons that were prepared for studies relating the carbon properties to the content of metal cations in the coal were sent to a commercial laboratory for multiple-point surface area determination and porosity analyses. In general, the BET-specific surface areas of the carbons were low (Table 4), ranging from $245 \mathrm{~m}^{2} / \mathrm{g}$ for the carbon from the high-sodium, low-calcium coal to $370 \mathrm{~m}^{2} / \mathrm{g}$ for the high-calcium, low-sodium carbon. The total pore volumes were also relatively low, that is, $0.14 \mathrm{cc} / \mathrm{g}$ for the high-sodium, low-calcium carbon and 0.20 for the highcalcium, low-sodium carbon.

The pore-size distributions for these carbons are decreasing functions with respect to pore size. Thus most of the pore volume is of fine micropore dimensions. The plots of pore size versus poresize distribution are similar for the three carbons. The average pore diameter calculated for a cylindrical model varied from 2.0 to $2.3 \mathrm{~nm}$. Using the formula for a slit model porosity, the average width is about $1.1 \mathrm{~nm}$. Because of the long equilibration times observed, the pore dimensions may be as small as $0.35 \mathrm{~nm}$. 


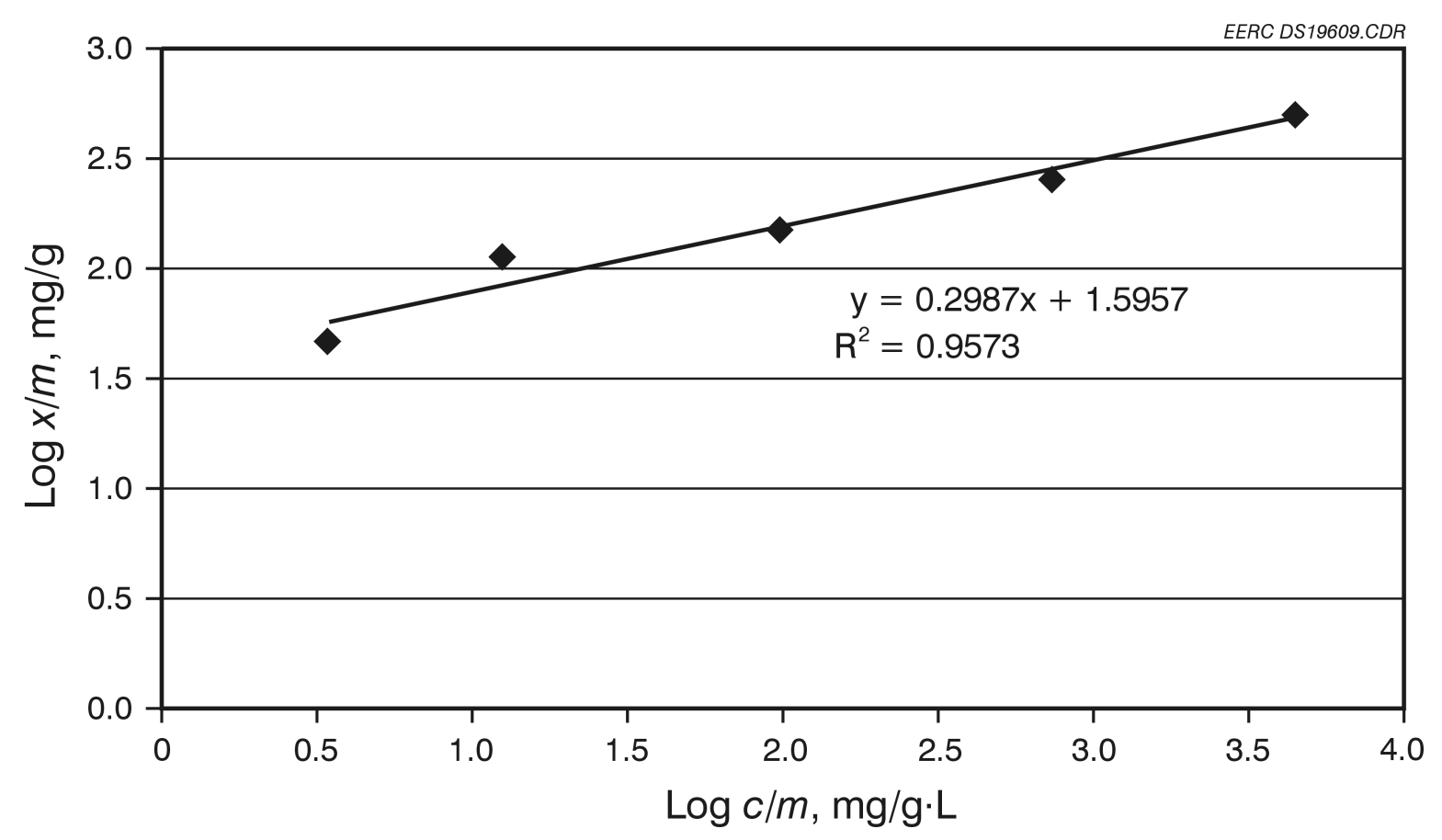

Figure 12. Normalized toluene isotherm for low-sodium, low-calcium carbon.

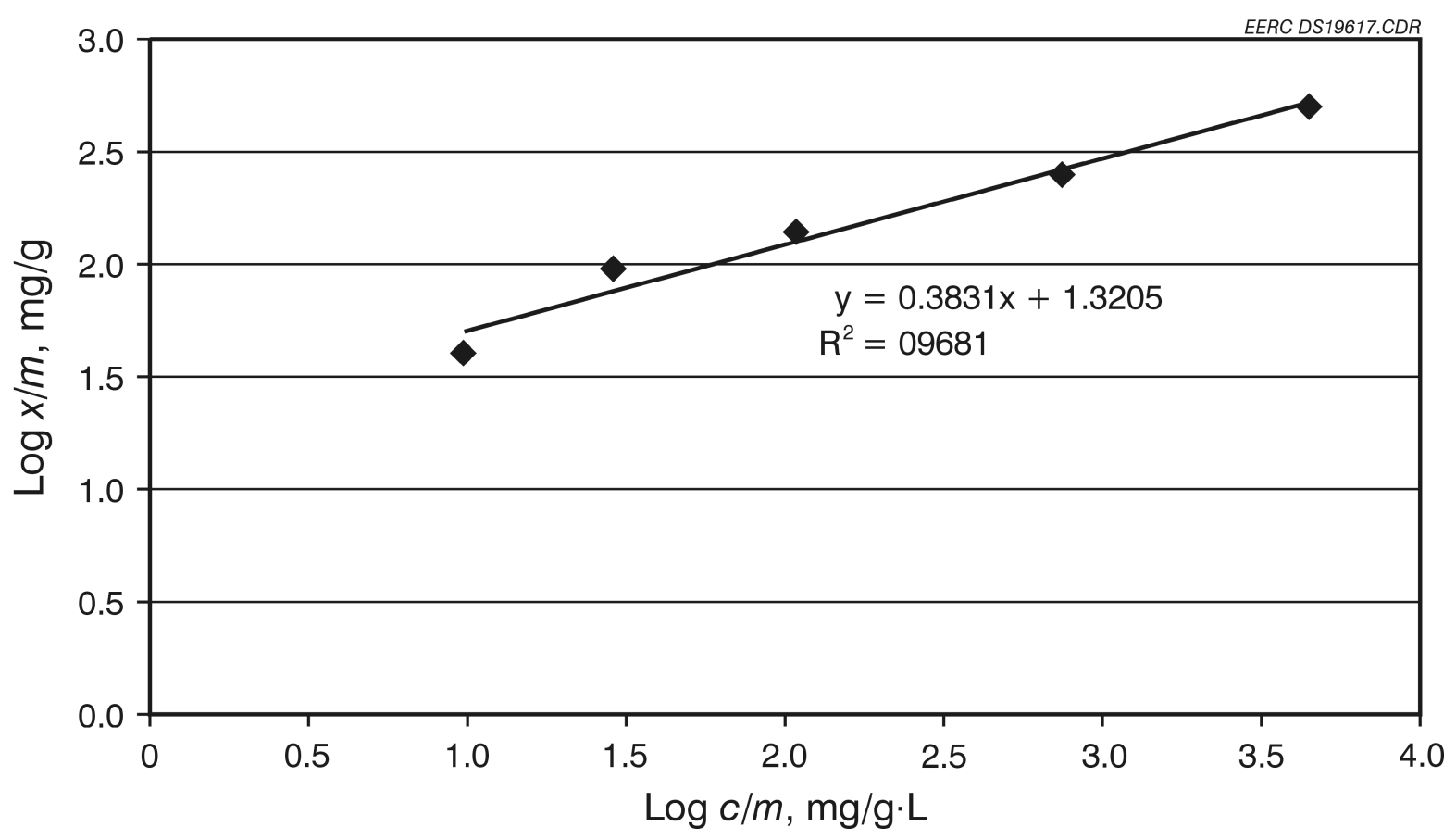

Figure 13. Normalized toluene isotherm for low-sodium, low-calcium carbon No. 2. 
Table 4. Activated Carbon Surface Area and Porosity Data

\begin{tabular}{lccc} 
Metal Content & $\begin{array}{c}\text { BET Surface } \\
\text { Area, } \\
\mathbf{m}^{2} / \mathbf{g}\end{array}$ & $\begin{array}{c}\text { Pore Volume, } \\
\mathbf{c c / g}\end{array}$ & $\begin{array}{c}\text { Avg. Pore Width, } \\
\mathbf{n m}\end{array}$ \\
\hline High Sodium, Low Calcium & 245 & 0.14 & 1.2 \\
High Calcium, Low Sodium & 370 & 0.20 & 1.1 \\
Low Sodium, Low Calcium & 349 & 0.17 & 1.0 \\
$\begin{array}{l}\text { High Sodium, Low Calcium } \\
\text { (unwashed) }\end{array}$ & 250 & 0.15 & 1.2 \\
\hline
\end{tabular}

A sample of the high-sodium, low-calcium carbon was not washed with water after preparation as were the other three samples analyzed. It was conjectured that the unwashed carbon may contain sodium oxide, hydroxide, or carbonate blocking the pores and that this was washed away in the postcarbonization treatment. The BET data, however, are almost exactly the same as those of the corresponding washed carbon. Since, in fact, the solution becomes quite basic during water washing, the sodium bases are removed, but they must not have been blocking the micropores. Whether they block macropores is unknown, but they are easily removed in contact with water, and will not cause a problem in surface water treatment which is normally conducted at basic $\mathrm{pH}$ anyway.

A greater carbon burnout is expected for the more reactive sodium-containing coal during carbonization. The lower-BET surface area and pore volume for the high-sodium, low-calcium carbon is consistent with a smaller total number of micropores, which can be attributed to a greater loss of carbon in the burnout. The concomitant increase in macropores resulting from this burnout does not show up in the distribution data, since there is a relatively low area associated with these pores. The remaining micropores in the high-sodium, low-calcium carbon are then roughly similar in size to those resulting from carbonization of the other coals. But the average pore width as calculated using a slit model $(\mathrm{w}=2 \mathrm{~V} / \mathrm{S})$ is slightly larger for the high-sodium, low-calcium carbon. The average pore diameter calculated from a cylindrical model $(\mathrm{d}=4 \mathrm{~V} / \mathrm{S})$ is similarly slightly larger for the high-sodium, low-calcium carbon.

\section{SEM on Activated Carbons}

SEM photographs of the activated carbons prepared from the raw and exchanged coals were also analyzed, along with the corresponding microprobe data. The carbon resulting from activation of the raw high-sodium coal exhibited some areas with cracks that reveal a complex interior composed of micron-size features (Figure 14). Probe analysis of the grey carbon areas showed that a significant amount of sodium was associated with these carbon phases as well as the white mineral phases (as sodium calcium silicates, sodium calcium aluminosilicates, and sodium calcium sulfates). Thus, the sodium was not lost from organic structure during the charring and carbonization process and was available for catalysis of reactions of the steam with the carbon during activation. 


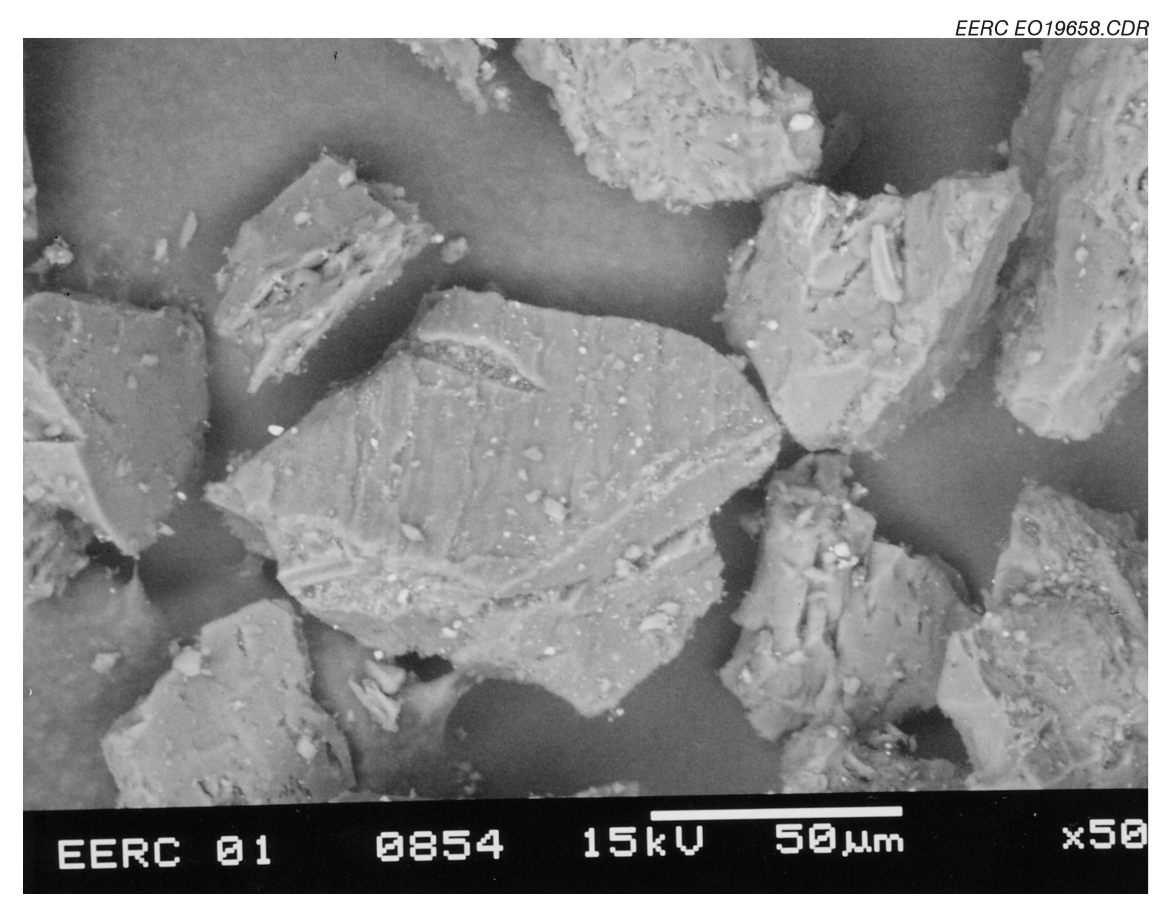

Figure 14. SEM microphotograph of high-sodium carbon.

SEM photographs of the activated carbon from the calcium-exchanged coal showed a series of parallel micron-sized slits resulting from cleavage of the carbon particles (Figure 15). Inside the slits were rough-looking submicron features. Probe analysis of the particles showed that the grey carbon phases contained no calcium. Only the white mineral phases contained calcium, as silicates, aluminosilicates, sulfates, and oxide. This finding is consistent with the composition of the original calcium-exchanged coal, which contained calcium only in the mineral phases. Thus, since the calcium does not appear to be located close to the carbon structure, it would not be available for catalysis during activation.

SEM photographs of the low-Ca, low-Na carbon prepared from the exchanged coal sample were also examined (Figure 16). Some of the particles contained the slit structures observed in the carbon from the calcium-exchanged coal. Thus there appears to be little difference in the particles from this and the calcium-exchanged carbon.

\section{CONCLUSIONS}

Activated carbons were prepared from three coals representing high-sodium, low-sodium-lowcalcium, and high-calcium compositions in two steps, an initial char formation followed by mild activation with steam to avoid excessive burnout. This set of carbons were characterized with respect to physical and chemical properties. The BET nitrogen adsorption isotherms gave relatively low surface areas (ranging from 245 to $370 \mathrm{~m}^{2} / \mathrm{g}$ ). Since the pore widths were also very small (1.0 to $1.2 \mathrm{~nm}$ ), the carbons are characterized as microporous; thus the low surface areas result from there 


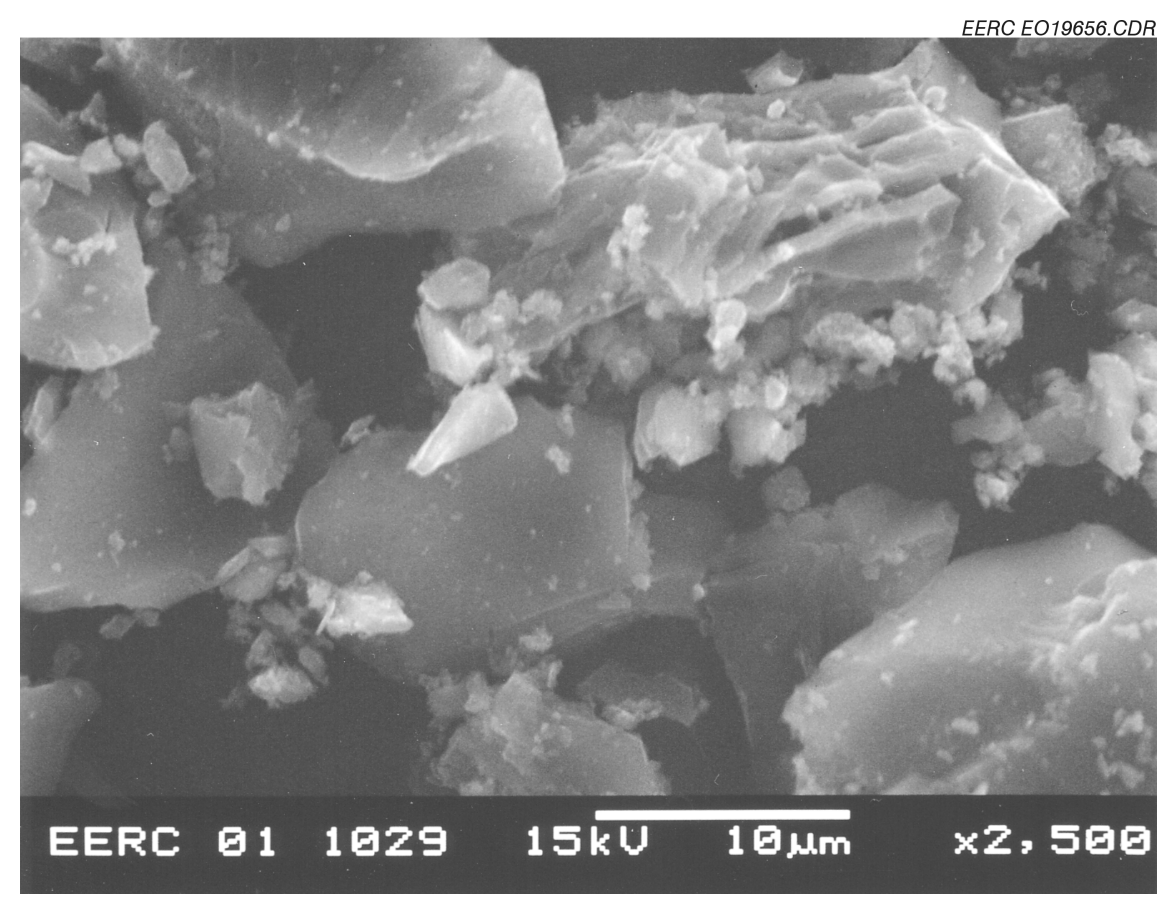

Figure 15. SEM microphotograph of high-calcium carbon.

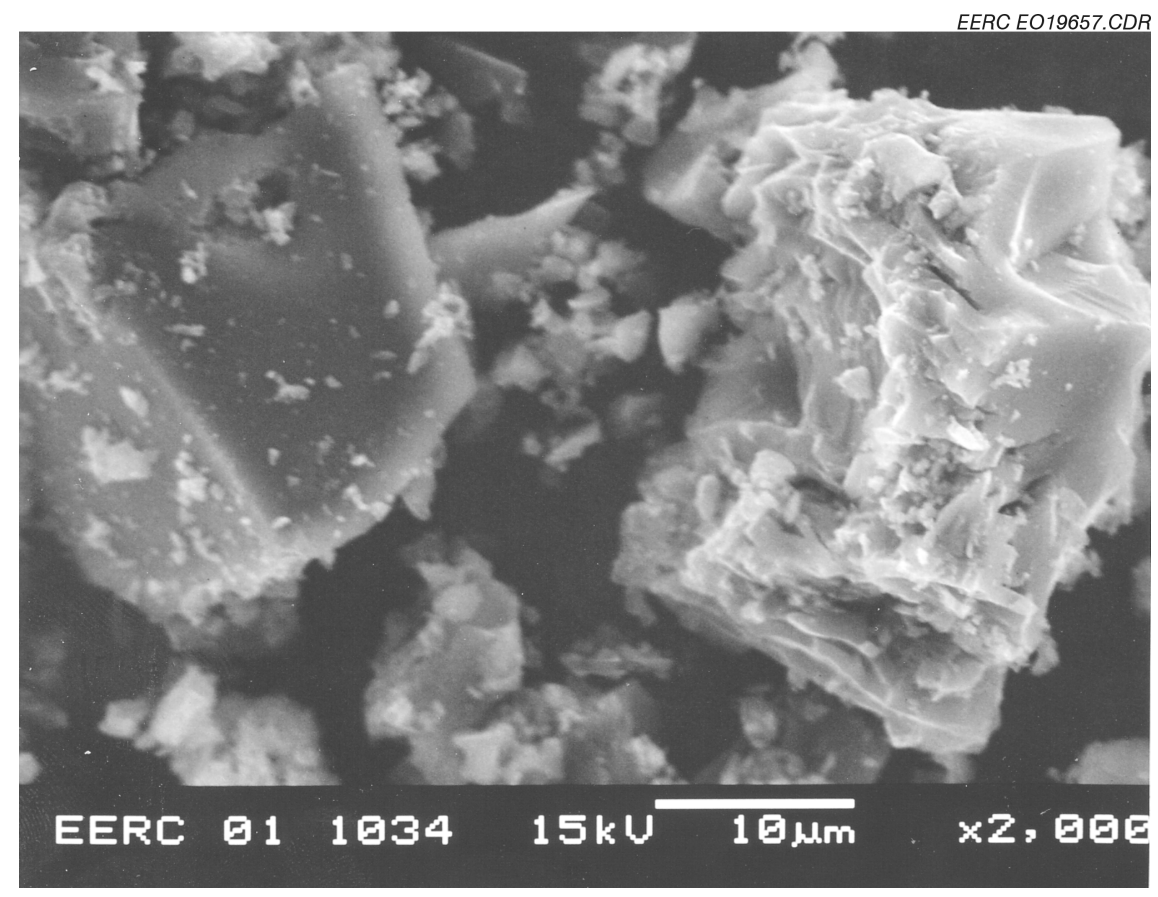

Figure 16. SEM microphotograph of low-sodium, low-calcium carbon. 
not being very many micropores. The macropore areas do not account for much area, so they are not really measured in this analysis.

The lowest-BET area was obtained for the high-sodium carbon, which can be attributed to enlargement of micropores as a result of sodium-catalyzed gasification reaction of the carbon structure. This hypothesis is consistent with the SEM microprobe analyses, which show that in both the coal and the activated carbon from this coal, the sodium is distributed over both the carbon structure and the mineral particles. Thus it is readily available for catalysis of gasification initially associated with carboxylate groups on the coal and then as sodium oxide or other active form in close proximity to the carbon.

In the exchanged coals, the sodium and other cations are mostly removed from the carbon structure of the coal, but addition of calcium did not effectively introduce calcium into the carbon structure. This was indicated by the SEM microprobe studies. Thus there was not much catalysis of gasification during steam activation, and the mild activation conditions that were used did not effectively generate a large micropore volume.

The adsorption activities were determined for the three activated carbons using tests that would represent their use as potential PAC treatment agents for high-NOM surface water, such as that in northern Minnesota which drains from peat deposits. In previous research, the lignite-derived carbons exhibited large capacities for the high-molecular-weight humate contaminants in such water. In this work, the humate isotherms for the carbons were analyzed via a modified Freundlich plot with normalized $\mathrm{c} / \mathrm{m}$ to correct for the wide molecular weight distribution and improve linearity. The intercept representing the $\mathrm{K}$ value for the high-sodium carbon was much larger than that of the commercial Calgon 400 carbon as well as that of the high-calcium and the low-sodium, low-calcium carbon prepared in this work. Thus the high-sodium carbon will be considerably more effective in reducing the humate concentration for a given carbon dosage. The slopes of the normalized Freundlich plots for the various carbons including the Calgon 400 were similar. These results are consistent with the hypothesis that only the larger pores are effective for binding the large humate molecules and that the larger pores developed during activation of the high-sodium char give the appropriate macropore structure for humate binding.

Toluene isotherms were also performed for the set of carbons. These indicated that the highcalcium carbon and the low-calcium, low-sodium carbon were superior to the high-sodium carbon, but not as effective as a Calgon 400. This is consistent with the low-BET surface areas observed for the lignite-derived carbons, and thus there are a lower number of sites for binding the smaller toluene molecule in these carbons.

Further work is needed to optimize the conditions for activation of the exchanged coals. It is clear that the activation times or temperatures could be longer and higher, respectively, to develop more micropores and generate activated carbons with higher capacity for smaller molecules. This would give them higher potential for wider usage in treatment of water with other types of contaminants, such as isoborneol, atrazine, or chlorinated hydrocarbons. To compete effectively in the market, less expensive methods for demineralization of the lignites should also be investigated. 
Of primary interest would be sulfurous acid, which has been effective for removing sodium from lignite.

More effective ways to utilize the high-sodium carbon in water treatment should also be investigated. The effect of coaddition of small amounts of alum with the lignite-derived carbons is currently being examined.

\section{REFERENCES}

Kilduff, J.E.; Karanfil, T.; Chin, Y.-P.; Weber, W.J. Environ. Sci. Technol. 1996, 30, 1336. 
